\title{
Blasinstrumente aus dem europäischen Jungpaläolithikum. Fundmaterial, Interpretation und musikwissenschaftliche Aspekte
}

\author{
Michael Praxmarer
}

\section{Zusammenfassung}

Die vorliegende Studie behandelt die als potentielle Blasinstrumente angesprochenen Funde des europäischen Jungpaläolithikums, wobei eine typologische Unterteilung in Phalangenpfeifen, perforierte Knochen, Einzellängsflöten ohne Grifflöcher und Panflöten sowie intentionell hergestellte Blasinstrumente erfolgt. Neben Instrumenten, bei denen der Ton durch Brechen des Luftstroms an einer Schneide bzw. Kante erzeugt wird, werden in diesem Beitrag auch Rohrblätter sowie die klangverzerrenden Mirlitons berücksichtigt. Versuche mit ersten experimentalarchäologischen Repliken liefern Argumente für die bessere Eignung als Flöten- oder Rohrblattinstrument. Die frühesten archäologisch überlieferten eindeutigen Blasinstrumente fungierten als Katalysator für eine hoch entwickelte Sprache und die bildenden Künste. Musik ist damals wie heute nicht nur eine unterhaltsame Nebensache, sondern eine wichtige soziokulturelle Triebkraft, die es vermag, verschiedenste Menschen zu verbinden.

\section{Schlüsselbegriffe}

Jungpaläolithikum, Blasinstrumenttypen, Jagdpfeifen, Melodieinstrumente, Musik und Sprache, Musikarchäologie, Europa.

\begin{abstract}
Aerophones in the European Upper Palaeolithic. Finds, Interpretation and Musicological Aspects

This study deals with a class of archaeological finds from the European Upper Palaeolithic that are usually referred to as potential flutes. In this paper, these artifacts are divided typologically into phalangeal whistles, perforated bones, single flutes without finger holes, panpipes, and intentionally manufactured aerophones. In addition to instruments in which the sound is generated by breaking the air flow at a cutting edge, reeds and sound-distorting mirlitons are also discussed in this paper. Experiments using replica instruments provide further arguments on the question of flute- or reed-blowing. The first unquestionably human-made aerophones uncovered by archaeology brought in changes in language and a flourishing of the visual arts. Music is not just an entertaining minor matter, but an important socio-cultural driving force that is able to unite different humans.
\end{abstract}

\section{Keywords}

Upper Palaeolithic, types of aerophones, hunting whistles, melodic instruments, music and language, music archaeology, Europe.

\section{Einleitung}

Das Korpus an Musikinstrumenten des Jungpleistozäns ist groß und besteht aus Schwirrhölzern, Schrapern, Trommeln, ${ }^{1}$ Musikbögen, ${ }^{2}$ Rasseln, Klangsteinen (Tab. 1, Abb. 1) und Blasinstrumenten (Tab. 2, Abb. 2). ${ }^{3}$ Die bedeutendsten Fundorte Europas, die mit der Musik des Jungpaläolithikums in Zusammenhang stehen, sind Hohle Fels, Geißenklösterle, Vogelherd und Brillenhöhle (alle Schwäbische Alb, Deutschland), Roche de Birol bei Lalinde und Isturitz (beide Frankreich), Kammern-Grubgraben (Niederösterreich) sowie Mezin (Südukraine). ${ }^{4}$ Zusätzlich zu den Musikinstrumenten dieser Fundorte gibt es indirekte ikonografische Hinweise auf das Musizieren im Jungpaläolithikum, wie z. B. die tanzenden Figuren aus Gönnersdorf (Rheinland-Pfalz) oder die als „Fanny“

\footnotetext{
1 Z. B. Holdermann 2001. - Morley 2003. - IbÁÑeZ et al. 2015, 282.

2 Kerig 2009, 329 und Abb. 404. - D’Errico et al. 2003, 34 und Abb. 8 a.

3 Durchaus denkbar, wenn auch nicht belegt, sind u. a. Hörner, Alphörner, Didgeridoos, Klapperstöcke, Stabzithern, Stampfröhren, Maultrommeln und Schlitztrommeln. Da die Verwendung von gebranntem Lehm im fortgeschrittenen Jungpaläolithikum(Gravettien) in Dolní Věstonice sowie in Krems-Wachtberg nachgewiesen ist, wäre auch die Anfertigung von Gefäßflöten aus Lehm theoretisch möglich gewesen.

4 Siehe dazu den Überblick bei Münzel, Conard 2009, 317 und Abb. 388. - Neben diesen Fundorten sind noch eine ganze Reihe weiterer zu nennen, siehe RotTLÄNder 1996, bes. Tab. 1. - Fages, Mourer-Chauviré 1982. - Viele Funde stammen allerdings aus den Grabungen des 19. und frühen 20. Jhs.: Morley 2013, 37.
}

5 Bosinski, Fischer 1974. 


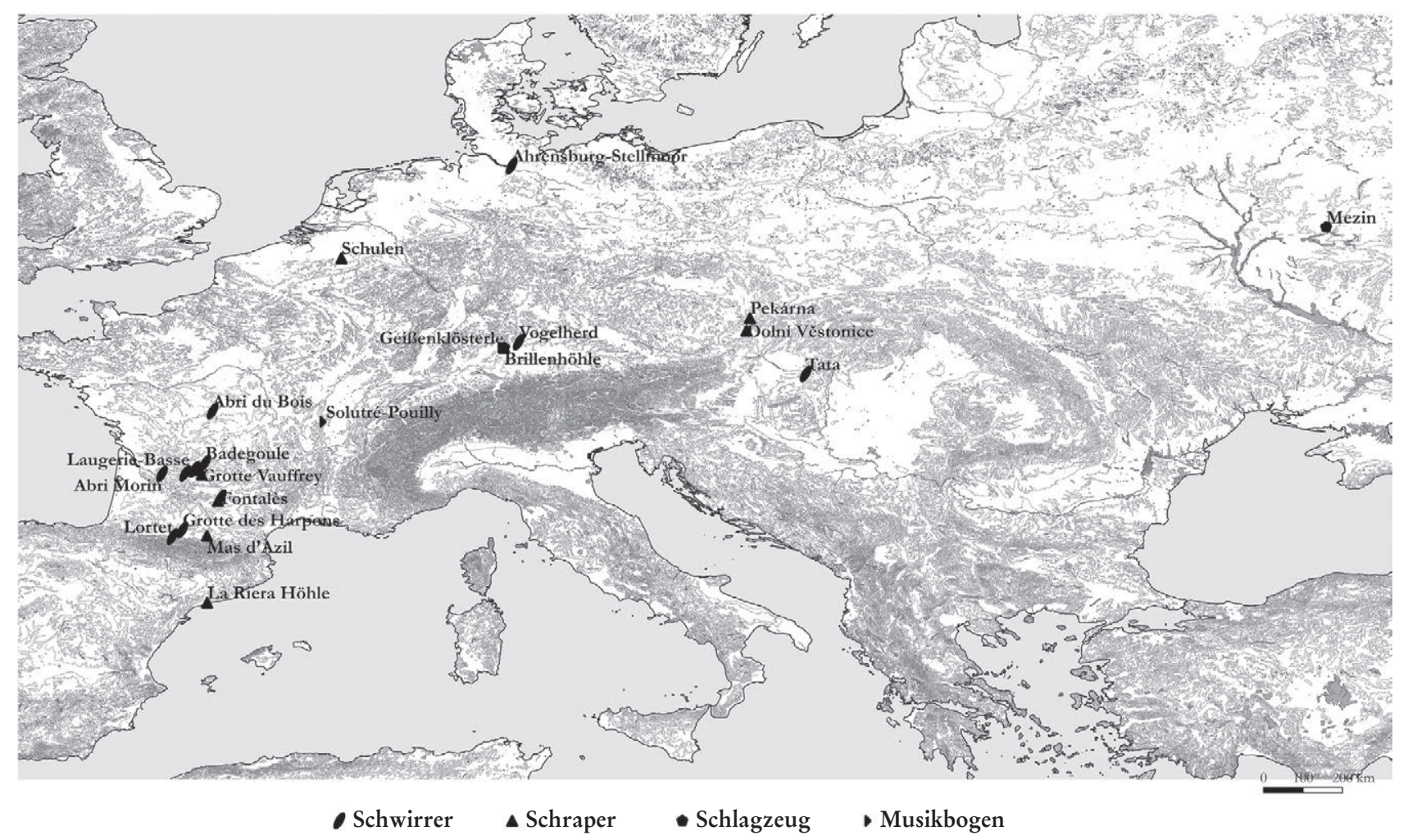

Abb. 1. Verbreitungskarte der Musikinstrumente des europäischen Jungpaläolithikums (Blasinstrumente ausgenommen).

bezeichnete Statuette einer Tänzerin vom Galgenberg bei Stratzing (Niederösterreich). ${ }^{6}$

Das früheste intentionelle Anbringen von Grifflöchern und damit die erste Herstellung von Melodieinstrumenten mit fixer Intervallbildung tritt synchron mit anderen Zeugnissen menschlicher Kunst auf, wie zum Beispiel Malereien auf Höhlenwänden. ${ }^{7}$ Vermeintlichen und tatsächlichen Blasinstrumenten des Jungpaläolithikums haben sich seit den 1990er Jahren mehrere Autorinnen und Autoren gewidmet. Paula Scothern listet 106 (angebliche) Flöten

6 Neugebauer-Maresch 1989. - Neugebauer-Maresch 1990. - Weitere indirekte Nachweise von Musik wären z. B. das der sogenannten „Fanny“ vom Galgenberg sehr ähnliche Halbrelief von Geißenklösterle (Müller-Beck 2001a, 49-50. - MÜLler-BeCK 2001b, 65) sowie die „Zauberer“ von Trois Frères aus Frankreich (Holdermann 2001, 89), ein vermummter Tänzer vom Abri Mège bei Teyjat (Franz 1969, 77), ein (tanzender?) Wisent-Mann aus der Chauvet-Höhle (Сцотtes, Lewis-Williams 1997, 45 und Abb. 41), die Wisent-Frauen von Peche Merle (Lorblanchet 1997, 15, 180) sowie die Hornrassel bzw. der Schraper in der Hand der Venus von Laussel (SEEBERGER 2002, 67).

7 Berghaus 2004. oder Pfeifen auf. ${ }^{8}$ Lana Carol Neal spricht von 200 Artefakten des Jungpaläolithikums, die als (mögliche) Flöten klassifiziert wurden; dazu kommen perforierte Objekte, die als Pfeifen oder Stimmenverzerrer für die Jagd tauglich sind. ${ }^{9}$ Bei Iain Morley findet sich der Hinweis auf 144 frühe Flöten (ohne Phalangenpfeifen), ${ }^{10}$ wobei sich darunter mehrere Fundstücke befinden, die Untersuchungen zufolge nicht künstlichen Ursprungs sind, sondern durch Tierverbiss entstanden. ${ }^{11}$

Im vorliegenden Beitrag wird eine Übersicht über diese Objekte geboten, wobei das erschlossene Fundmaterial typologisch in Phalangenpfeifen, natürlich perforierte Knochen, ${ }^{12}$ Einzelflöten ohne Grifflöcher und Panflöten (Abb. 3) sowie intentionell hergestellte Blasinstrumente

8 SCOTHERN 1992.

9 Neal 2013, 60-61.

10 Nach Morley 2013, 34-35, 327-377 und Taf. 1-2.

11 Albrecht et al. 1998. - Holdermann, Serangeli 1998.

$12 \mathrm{Zu}$ Tierverbiss und anderen Einwirkungen auf prähistorische Fundstücke siehe D’Errico, Villa 1997. - D'Errico et al. 1998. D’Errico 2002. - D’Errico et al. 2003. 


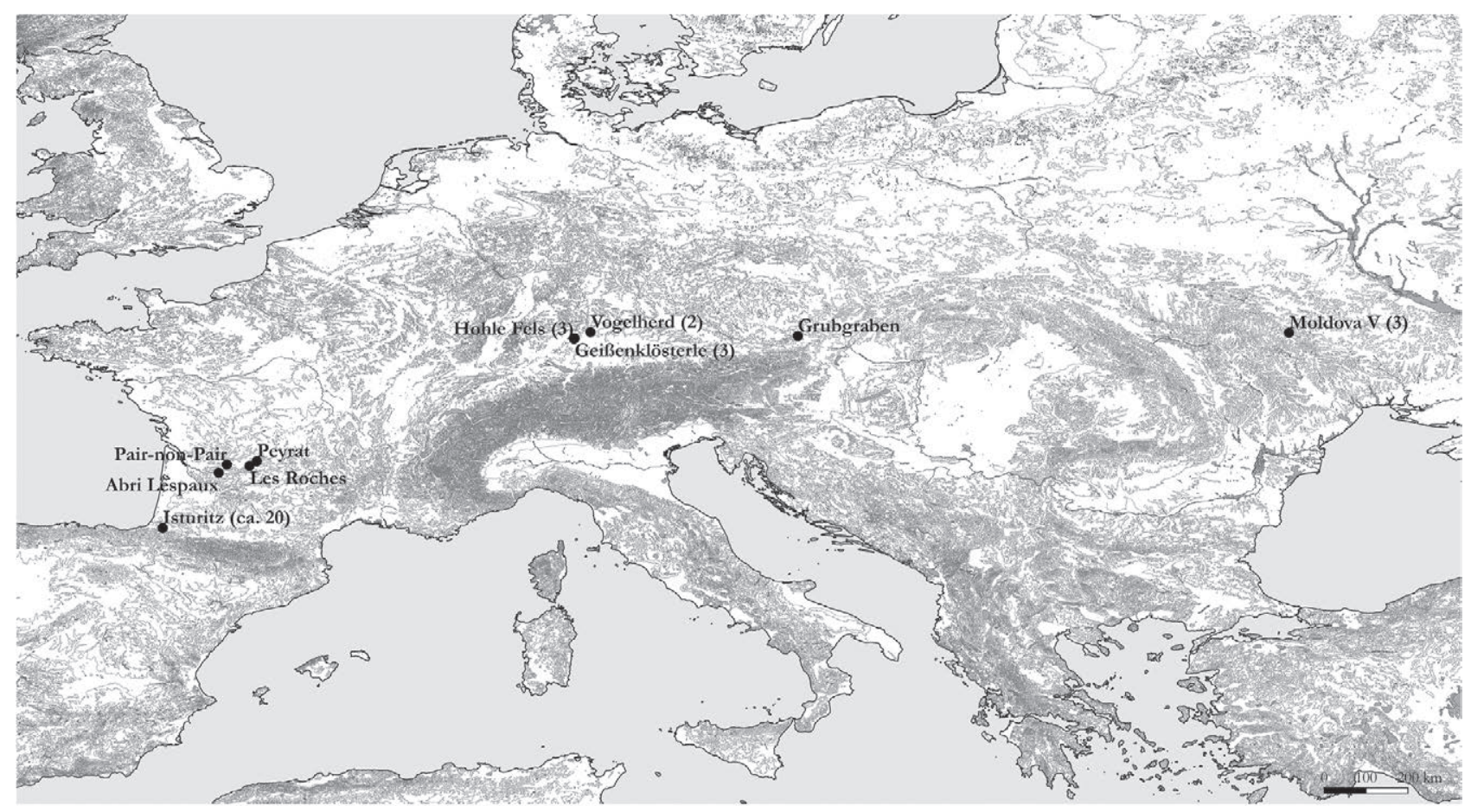

Abb. 2. Verbreitungskarte der intentionell hergestellten Blasinstrumente des europäischen Jungpaläolithikums.

(Abb. 4) unterteilt wird. Der Verfasser versucht, eindeutige Blasinstrumente im musikalischen Sinne von reinen Jagdoder Signalinstrumenten zu unterscheiden. ${ }^{13}$

\section{Tatsächliche und vermeintliche Blasinstrumente des Jungpaläolithikums}

\subsection{Phalangenpfeifen}

Phalangenpfeifen ${ }^{14}$ sind einfache Signalpfeifen mit einem Loch, die aus den von Natur aus hohlen Finger- bzw. Fußgliedknochen vor allem von Rentieren und ähnlichen Geweihträgern angefertigt wurden (Abb. 3/1).

13 Diese Unterscheidung erfolgt im Gegensatz zu Neal, die lediglich von „proven Upper Paleolithic flutes“ spricht: NEaL 2013, 46-47.

14 Der Begriff „Pfeife“ für eintönige Flöten geht auf SEEwald 1934 zurück und wurde auch von Bernadette Käfer für die Pfeife aus Kammern-Grubgraben (Abb. 3/1) herangezogen: KäFER 1998, 13 und Anm. 2. - Im Sinne einer systematischen Ordnung der Musikinstrumente ist der Begriff „Pfeife“ schwer zu fassen. Im Laufe der Musikgeschichte wechselt die Bedeutung von Blasinstrument im Allgemeinen zum Synonym für alle Holzblasinstrumente bis hin zum heutigen umgangssprachlichen Gebrauch des Wortes für die kleine, hoch und scharf klingende Flöte.
Phalangenpfeifen sind in den Inventaren des gesamten Jungpaläolithikums und bis ins Neolithikum belegt. Obwohl künstlich perforierte Objekte bereits im Mittelpaläolithikum auftauchen, ${ }^{15}$ gibt es an der von Ivan Turk und Boris Kavur postulierten Existenz von intentionell hergestellten Phalangenpfeifen im Moustérien ${ }^{16}$ berechtigte Zweifel. In jungpaläolithischen Kontexten treten sowohl sorgfältig

15 Z. B. an einigen afrikanischen Fundstellen wie Blombos, Loiyangalani-River-Valley, Qued Djebanna, Grotte Zouhra: CAldwell 2009, 73-74. - Perforierte Muscheln sind aus Es-Skhul (Israel) um 100.000-150.000 vor heute und aus Blombos (Südafrika) um 75.000 vor heute datiert: VANHAEREN et al. 2006. - Der durchbohrte Wolfszahn aus der Repolusthöhle (Steiermark) hat allerdings inzwischen eine Uminterpretation erfahren. Zwar weist er Herstellungs- wie Gebrauchsspuren auf, allerdings datiert er wohl eher ins Jungpaläolithikum: ModL, PACHER 2014, 193-194. Beim mit dem Wolfszahn vergesellschafteten durchbohrten Langknochenfragment aus der Repolusthöhle muss man aufgrund des völligen Fehlens sichtbarer Herstellungs- und Gebrauchsspuren ander Durchlochung nunmehrvon natürlichen Entstehungsursachen ausgehen: Modi, Pacher 2014, 189. - Zweifel gibt es auch an der Zuweisung der durchbohrten Objekte der Grotte du Renne (Yonne, Frankreich) ins Châtelperronien: Mellars 2010.

16 Turk, Kavur 1997, 179. 
gearbeitete und eindeutig künstlich gelochte Objekte als auch solche mit Spuren von Tierverbiss auf. ${ }^{17}$

Seit den ersten Funden 1860 in der Höhle von Aurignac (Haute-Garonne, Frankreich) werden Phalangenpfeifen als Jagdpfeifen interpretiert. Ob die perforierten Phalangen allerdings direkt als Musikinstrumente anzusprechen sind, ist fraglich. Claus-Stephan Holdermann bezeichnet sie als ein „Mittel frühester Kommunikation über die Sprache hinaus“ ${ }^{18}$ Im engeren Sinn läge nach Andreas Meyer ein kleines Flöteninstrument vor, „das als Eintoninstrument primär zur Signalgebung und als Lockpfeife, z. B. für Jäger oder Vogelfänger, dient, also im außermusikalischen Kontext gebraucht wird“". ${ }^{19}$ Studien im Nordwesten Kanadas haben gezeigt, dass Rentiere mit einem besonderen Verhalten auf Phalangenpfeifen reagieren: Ertönt ein Pfiff, bleibt das Tier regungslos stehen, ertönen mehrere Pfiffe, legt sich das Tier auf den Boden. ${ }^{20}$ Ähnliche Reaktionen wurden auch bei Experimenten an der finnisch-russischen Grenze beobachtet. Eine Herde Rentiere ließ sich zuerst durch Pfiffe aus Rentierphalangenflöten anlocken. Nachdem die Pfiffe wiederholt wurden, legten sich die Tiere in den Schnee. ${ }^{21}$ Die Klangverwandtschaft der Flötentöne zu Tierschreien ${ }^{22}$ könnte eine Erklärung dafür sein. Reste von 650 erjagten Tieren in Ahrensburg-Stellmoor (SchleswigHolstein) betonen die Wichtigkeit der Rentierjagd im eiszeitlichen Europa. ${ }^{23}$ Nach dem Wildpferd (und zeitweise Mammut) gehörten Rentiere zur wichtigsten Beute auf der Schwäbischen Alb. ${ }^{24}$ In Michel Lorblanchets Reihe der am häufigsten abgebildeten Tiere in der paläolithischen Höhlenmalerei findet sich das Rentier immerhin an neunter Stelle (vor Bär, Löwe und Nashorn). ${ }^{25}$ Michel Dauvois gelang es, mittels Frequenzmessungen Analogien von Phalangenpfeifen zu pyrenäischen Hirten-Pfeifsprachen aufzuzeigen. Auch stellte er fest, dass Phalangenpfeifen mit großen

17 D’Errico et al. 1998. - So hat man in modernen Hyänenfäkalien gelochte Phalangen nachgewiesen, die große Ähnlichkeiten mit jenen aus urgeschichtlichen Fundzusammenhängen aufweisen: Holdermann 2001, 92. - Eine Aufstellung der Fundorte von angeblichen Phalangenpfeifen findet sich bei MORLey 2013, 378-388 und Taf. 3.

18 Holdermann 2001, 92.

19 Meyer, Meyer, Betz 1995, 559-560.

20 NeAl 2013, 22-23.

21 Morley 2013, 104-105.

22 WiLson 1896, 524 vergleicht den Flötenton mit dem Schrei einer Katze.

23 Junkmanns 2013, 83-84.

24 Napierala, Uerpmann 2009, 186 und Abb. 213.

25 Lorblanchet 1997, 59.
Anblaslöchern über Distanzen von bis zu 1,25 km deutlich hörbar sind. ${ }^{26}$

\subsection{Perforierte Knochen als vermeintliche Aerophone}

Während sich in der älteren Literatur eine große Anzahl potentieller Flöten findet, ${ }^{27}$ ist die anthropogene Natur vieler dieser Flöten heute umstritten. Der im Jahr 1995 erfolgte Fund eines angeblichen Blasinstruments in der Höhle Divje babe I in Slowenien (Abb. 3/2) durch Turk ${ }^{28}$ führte dazu, dass zumindest auf Seiten der Kritiker alle sogenannten „Bärenknochenflöten“ fortan nicht mehr als Musikinstrumente galten. ${ }^{29}$ Claus-Stephan Holdermann und Jordi Serangeli diskutieren zehn Beispiele perforierter Höhlenbärknochen aus Österreich und den angrenzenden Gebieten, die in der Vergangenheit als Flöten angesprochen wurden. Allerdings konnte weder ein Beweis für das Entfernen der Spongiosa noch ein von Menschenhand geschnitztes Loch gefunden werden. ${ }^{30}$ Weitere Experimente zur Entstehung der Löcher lassen klar auf Tierverbiss schließen. ${ }^{31}$ Dass das Artefakt aus der Höhle Divje babe I wahrscheinlich ein Ökofakt ist und nicht durch menschliche Einwirkung zu seiner heutigen Form kam, zeigt eine Reihe von Studien von Francesco d'Errico et al., ${ }^{32}$ wenn auch die jüngste Publikation von Matija Turk et al. den artifiziellen Charakter des Objekts neuerdings zu beweisen versucht. ${ }^{33}$ Dennoch könnten natürlich perforierte Knochen als Vorbilder für spätere Blasinstrumente fungiert haben. Der Einsatz als Jagdpfeife oder Stimmverzerrer wäre darüber hinaus durchaus möglich. Es ist festzuhalten, dass ein sehr geübter Spieler wie Ljuben Dimkaroski jegliche Melodie in einem Spektrum von 3,5 Oktaven mit einem Nachbau des Knochens spielen kann. ${ }^{34}$

26 Dauvois 1989. - Siehe auch Caldwell 2009, 68. - Dauvois hat Frequenzmessungen am vollständigsten Isturitz-Instrument (mit vier Löchern) vorgenommen und die Amplituden von Schwirrhölzern und Schrapern untersucht. Schließlich testete er die Resonanzen in Höhlen und analysierte die Klänge von Tierrufen und Lithophonen: Dauvois 2005.

27 Zagiba 1976. - RotTläNDER 1996, 36-37.

28 Turk 1997b, 20-21. - Turk 1997c, 26 und Abb. 2.1.

29 Bes. Albrecht et al. 1998. - Albrecht, Holdermann, Serangeli 2001. - D’Errico 2002.

30 Holdermann, Serangeli 1998.

31 Albrecht et al. 1998.

32 D’Errico, Villa 1997. - D’Errico et al. 1998. - D’Errico 2002.

- D’Errico et al. 2003. - Nowell, D’Errico 2007.

33 Turk et al. 2018.

34 Turk et al. 2018, 699. - Vgl. darin auch die Beiträge von Ljuben

Dimkaroski und François Zoltan Horusitzky. 


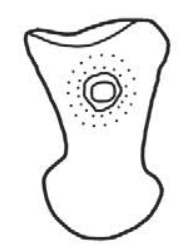

1

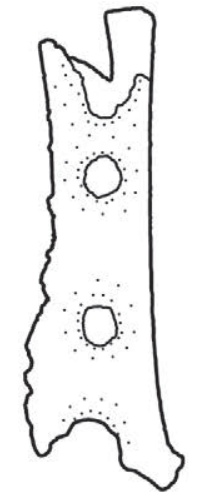

2
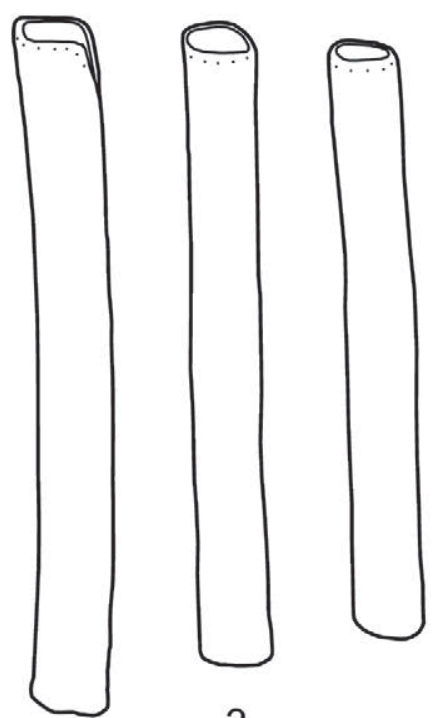

3

Abb. 3. Typen von Blasinstrumentenfunden aus dem europäischen Jungpaläolithikum. - 1. Artifiziell gelochte Rentierphalanx aus Kammern-Grubgraben (nach KäFER 1998, Abb. 29). - 2. Perforierter Höhlenbärknochen aus der Höhle Divje babe I (nach Turk, DirJec, Kavur i995, 289). - 3. Einzellängsflöten oder Panflöte aus der Grotte de Gourdan (nach Neal 2013, 31 und Abb. 2-1).

In Tabelle 3 (siehe weiter unten) sind jene Funde von perforierten Knochen aufgelistet, die als vermeintliche Aerophone - mitunter als Jagdmittel - gesehen werden.

Der Mandibula eines Höhlenbären aus der Potočka zijalka-Höhle (Slowenien) gesteht Otto Seewald artifiziellen Charakter zu. Sie stammt aus den Aurignacien-Schichten 4 oder 5 und ist damit etwas jünger als das Objekt aus Divje babe I. ${ }^{35}$ Von den südamerikanischen Chorotí sind laut Seewald Flöten aus kleinen Tierschädeln, deren Öffnungen bis auf das als Anblasloch dienende Hinterhauptsloch verklebt werden, überliefert. ${ }^{36}$ Auf der Replik des Bärenunterkiefers aus der Potočka zijalka-Höhle konnte man z. B. die Töne ${ }^{1}$, $c^{2}, \operatorname{cis}^{2}, d^{2}$, dis $^{2}$ und $g^{2}$ erzeugen. Die Kieferspitze wäre eine natürliche dreieckige Anblasvorrichtung. ${ }^{37}$ Aus der Kents Cavern bei Torquay (Devonshire, England) führt Seewald noch das $11 \mathrm{~cm}$ lange Hasenfemur-Bruchstück aus dem Magdalénien an - mit sechs kleinen Löchern in unregelmäBiger Anordnung. ${ }^{38}$

\footnotetext{
35 Turk, Kavur 1997, 182 und Abb. 12.1/5.

36 SeEwald 1934, 19-21 und Taf. I/8.

37 Omerzel-Terlep 1997, 211-212.

38 Seewald i 934, 35 und Taf. II/2. - Siehe auch Fages, Mourer-

Chauviré 1983, 102 und Abb. 6/13.
}

In die Kategorie der perforierten Knochen fallen laut Turk und Kavur folgende Objekte: Aus der IstállóskőHöhle (Ungarn) stammt ein Femur eines juvenilen Höhlenbären mit drei Löchern. Turk und Kavur sprechen von einem abgeschnittenen Ende und dem Entfernen der Spongiosa. ${ }^{39}$ Ein erfolgreiches Anblasen als Querflöte ( $a, b^{\mathrm{b}}, \mathrm{b}$, c) ist bei Vincent Megaw verzeichnet. ${ }^{40}$ Aus der Ilsenhöhle bei Ranis (Thüringen) stammt das Mittelstück eines Säugetier-Langknochens mit fünf Löchern. Die dazugehörigen Steingeräte werden dem Ende des Mittel- oder dem Beginn des Jungpaläolithikums zugerechnet. ${ }^{41}$ Gerd Albrecht et al. sehen keinen Hinweis auf menschliche Bearbeitung der Ulna eines Schweines aus der Ilsenhöhle. ${ }^{42}$ Bei Morley fällt das Fundstück in die Kategorie angeblicher Flöten - im Gegensatz zu ursprünglich als Flöten angesprochenen Objekten, die inzwischen als unwahrscheinlich gelten. ${ }^{43}$ Dasselbe trifft auf weitere von Albrecht et al. behandelte Vertreter zu. Die Tibia eines juvenilen Höhlenbären mit vier Löchern

\footnotetext{
39 Turk, Kavur i 997, 181-182 und Abb. 12.1/3.

40 Megaw 1960, 7-8 und Taf. II/10. - RotTländer 1996, 36.

41 Turk, Kavur 1997, 183.

42 Albrecht et al. 1998, 6-7 und Abb. 3/2.

43 Morley 2013, Appendix Taf. 1-2.
} 
in Zickzack-Formation stammt aus dem Lieglloch (Steiermark) und wird in das Aurignacien datiert. ${ }^{44}$

Zwar sind nach heutigem Untersuchungsstand die perforierten Knochen nicht als Musikinstrumente zu klassifizieren, dennoch muss die Idee, dass Löcher in Knochen die Tonhöhe beeinflussen, irgendwo ihren Ursprung haben. In der Zeit der Entstehung der ersten komplexen Melodieinstrumente hatte man Zugang zu natürlich perforierten Knochen und so ist es denkbar, dass hier ein Zusammenhang besteht. Denn der natürliche Ursprung der Löcher schließt nicht aus, dass die Objekte als Instrumente genutzt wurden. ${ }^{45}$ Wie bei den Phalangenpfeifen sieht Neal in den vermeintlichen Aerophonen des Mittelpaläolithikums Jagdmittel. Dazu gehören die vermeintlichen MoustérienFlöten der Höhlen La Quina (Charente, Frankreich) und Lezetxiki (Guipúzcoa, Spanien). Erstere wurde im Mittelpaläolithikum, Châtelperronien und Aurignacien genutzt, letztere nutzte der Homo Heidelbergensis (ca. 150.000 vor heute) und später der Neandertaler (80.000-70.000 vor heute). ${ }^{46}$

\subsection{Einzellängsflöten ohne Grifflöcher und Panflöten}

Nach Victor Grauer ist die Längsflöte, wie sie auch für Panflöten benutzt wird, ein Musikinstrument, das mit der Auswanderung des modernen Menschen aus Afrika eng verbunden ist. ${ }^{47}$ Die korrekte Ansprache bei Erich Moritz von Hornbostel und Curt Sachs wäre Einzellängsflöte ohne Kernspalt und ohne Grifflöcher, wobei auf einer Seite verschlossene (gedackte) von offenen Röhren unterschieden werden. ${ }^{48}$

Wird in einem Blasinstrument ein Klang angeregt, entstehen sich überlagernde, mehr oder weniger resonierende, stehende Wellen. Diese Eigenschwingungen stehen bei beidseitig offenen Röhren in ganzzahligen Verhältnissen (1, $2,3, \ldots)$. Der Schalldruckgraph der Grundfrequenz hat die Form einer halben Sinusschwingung. Für die n-te Eigenschwingung mit der Wellenlänge $\lambda_{n}$ bedeutet das $n \cdot \lambda_{n} / 2=s_{o}$ woraus folgt $\lambda_{\mathrm{n}}=2 \cdot \mathrm{s}_{\mathrm{o}} / \mathrm{n}$. Die $\mathrm{n}$-te Eigenfrequenz errechnet sich also $f_{n}=v / \lambda_{n}=n \cdot v / 2 \cdot s_{o}\left(s_{o}\right.$ ist die Röhrenlänge, $v$ die Schallgeschwindigkeit in der Luft). Bei einem freien und einem festen Ende stehen die Eigenschwingungen in ungeradzahligem Verhältnis $(1,3,5, \ldots)$. Es entsteht eine Wellenform der Grundfrequenz, die im Schalldruckgraphen wie

44 Turk, Kavur 1997, 183 und Abb. 12.1/6.

45 Neal 2013, 17.

46 Neal 2013, 17, 19-20.

47 Grauer 2006. - Grauer 2011.

48 Hornbostel, SaChs 1914, 583-584. eine viertel Sinuswelle erscheint: $(2 \cdot n-1) \cdot\left(\lambda_{\mathrm{n}} / 4\right)=\mathrm{s}_{\mathrm{g}} ; \lambda_{\mathrm{n}}=4 \cdot \mathrm{s}_{\mathrm{g}} /$ $(2 \cdot \mathrm{n}-1) ; \mathrm{f}_{\mathrm{n}}=\mathrm{v} / \lambda_{\mathrm{n}}=(2 \cdot \mathrm{n}-1) \cdot \mathrm{v} / 4 \cdot \mathrm{s}_{\mathrm{g}}{ }^{49}$

Die Schneide einer Pfeife oder Flöte hat immer die Funktion eines offenen Endes. Die Klarinette ist als einseitig geschlossen zu berechnen. ${ }^{50}$ Bei den offenen Einzelflöten (bindewu) kann mittels eines Fingers oder auch mit einem organischen Pfropfen das untere Ende nach Belieben verschlossen werden. Mit dem Verschließen wird die Wellenlänge doppelt so lang und es ertönt die tiefere Oktave. ${ }^{51} \mathrm{Mit}$ zunehmendem Anblasdruck (Überblasen) einer beidseitig offenen Röhre erklingt die Oktave. Bei gedackten Einzelflöten ertönt beim Überblasen zunächst die Duodezime des Grundtones. $^{52}$

Nach ethnografischen Belegen sind Einzelflöten ohne Grifflöcher in Kombination mit alternierenden Gesängen ein möglicher Bestandteil des ältesten Musikstils der modernen Menschheit (bocketing style nach Grauer). ${ }^{53}$ Das Kennzeichen der Einzellängsflöten ohne Grifflöcher im ethnografischen Vergleich ist der Einsatz bei Gruppenperformances, wo mehrere Teilnehmer je eine einzelne Flöte spielen.

Als frühen archäologischen Beleg lassen sich nach Grauer zwei Vogelknochen von Kostenki (am Westufer des Don, Russland) anführen. Neben MammutknochenBehausungen und Venusfigurinen stammen von der Fundstelle „Musikinstrumente oder Lockpfeifen“ ${ }^{54}$ Grauer sieht in gestimmten Pfeifen bzw. Flöten ohne Grifflöcher eine afrikanische Erfindung und ein Äquivalent zu Sprache..$^{55}$ Die Basis dafür bildeten die Verhältnisse von 2/3 und 4/3. Unter Anwendung dieser Methode auf fünf Pfeifen ließe sich die pentatonische Folge C-D-E-G-A erzielen (chinesisch kung, shang, chiao, chib, yü oder unser do-re-mi-fa-so). ${ }^{56}$

49 Nach Hall 1997, 238-243 und Abb. 12/2-3. - Vgl. auch StumpF 1911, 37-38. - Benade 1988. - Auhagen 1994. - Meyer, Meyer, Betz 1995. - Kunej 1997, 195-196.

50 Hall 1997, 239, 273-275.

51 Im Orgelbau lässt sich damit die Flötengröße für tiefe Röhren halbieren.

$52 \mathrm{Zu}$ Überblasen und Rohrlänge siehe RotTLÄNDER 1996, 36.

53 Grauer 2006. - Grauer 2011.

54 Нiтchсоск 2019. - Siehe auch Grauer 2011, 154.

55 Grauer 2011, 217-219, 221.

56 Grauer 2011, 213-215. - Ein gedacktes Rohr mit 0,67 m Länge würde im Rechenbeispiel $128 \mathrm{~Hz}$ ergeben $(42 \mathrm{~Hz}$ oder eine Quinte höher); ein selbiges mit 1,33 m käme auf $64 \mathrm{~Hz}(21 \mathrm{~Hz}$ tiefer, also die tiefe Quinte); vom verkürzten 0,67 m langen Rohr noch einmal ein Drittel weggerechnet ergeben 0,44 m und $195 \mathrm{~Hz}$ und die Sekund bzw. Dezime des Grundtones; 0,29 m führen zu $294 \mathrm{~Hz}$ und der oktavierten Sext etc. 
Funde von möglichen Einzellängsflöten oder Panflöten sind im Magdalénien recht häufig anzutreffen. Beispiele wären nach Seewald Le Placard (Charente; ohne Schichtzugehörigkeit) und Gourdan (Haute-Garonne; aus dem oberen Magdalénien) (Abb. 3/3). Ein Exemplar aus Laugerie-Basse (Dordogne, Frankreich) ist mit drei Querrillen verziert. ${ }^{57}$ Nach Neal gehören einige Funde von möglichen Flöten ohne Grifflöchern aus Le Placard in das Solutréen. Mit weiteren 13, dem Magdalénien zugehörigen Artefakten stünde Le Placard somit an zweiter Stelle nach Isturitz, was die Zahl der potentiellen Blasinstrumente betrifft. Hervorzuheben sind die zwei Adlerknochen mit Gravuren $(14 \mathrm{~cm}$ und $11 \mathrm{~cm}$ ). In sechs Fällen wären Anblaskerben erhalten, auch beim längeren Adlerknochenfragment. Fast alle Exemplare sind graviert. Vier Pfeifen aus dem Magdalénien mit ungleicher Länge könnten zu einer Panflöte gehören. ${ }^{58}$ Neal listet weiters vier Pfeifen aus Dolní Věstonice (Mähren) auf, wobei in einem Fall Reste von Harz erhalten sind, die möglicherweise auf ein Block-Kanal-Prinzip hinweisen. Die Objekte sind nicht eindeutig datiert, aber wahrscheinlich als jungpaläolithisch anzusprechen. Des Weiteren behandelt sie die bereits erwähnten drei Röhren aus der Grotte de Gourdan (Lorthétienne-Schichten) (Abb. 3/3) sowie drei Vogelknochenfragmente aus der Grotte de Lortet (HautesPyrénées, Frankreich; Magdalénien). Zudem werden Vierergruppen aus dem Magdalénien aus Le Roc de Marcamps (Gironde, Frankreich; 3,7 cm, 4,3 cm, 4,9 cm und $7 \mathrm{~cm}$ ) und Raymonden (Dordogne; 3,9 cm, 4,1 cm, 13,2 cm und $14,7 \mathrm{~cm}$ ) erwähnt. Damit sieht Neal die Syrinx in der finalen Phase des Jungpaläolithikums. ${ }^{59}$ Inwiefern die jungpaläolithischen Panflöten aus geschlossenen Fundkontexten stammen, ist fraglich. Neal weist die verschieden langen Vogelknochenröhren ohne Grifflöcher demselben archäologischen Horizont der Fundstelle zu. ${ }^{60}$

Wulf Hein führt eine ganze Reihe von Knochenröhrenfunden an, ${ }^{61}$ die Dauvois ${ }^{62}$ als „Tuben“ angesprochen hatte: Geißenklösterle (früher als Schraper angesprochen), Gravettien des Hohle Fels, Magdalénien der Schussenquelle (Baden-Württemberg), ${ }^{63}$ des Petersfels (BadenWürttemberg $)^{64}$ und einiger kantabrischer Höhlen ${ }^{65}$ sowie

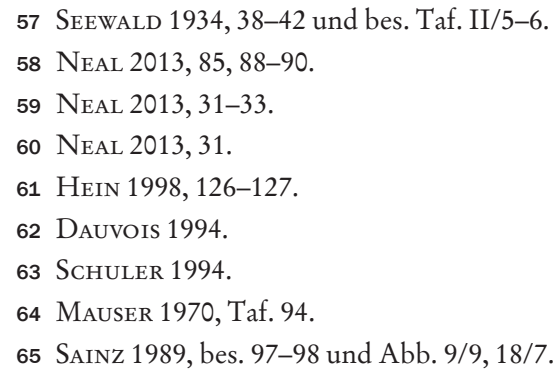

Schleswig-Holstein. ${ }^{66}$ Zwei mögliche Pfeifen aus der Grotte des Bernoux (Dordogne) gehören am ehesten in diese Kategorie, ${ }^{67}$ weiters fünf verzierte unbestimmte Knochenröhren und zwei Vogelknochen aus der Grotte de Spy in Belgien, die keine Fingerlöcher aufweisen. Es könnte sich um Aurignacien-Flöten oder -Pfeifen handeln. ${ }^{68} \mathrm{Nach}$ Morley wäre auch das $104 \mathrm{~mm}$ lange Fragment eines verzierten Vogelknochens aus Wildscheuer (Hessen) hier einzureihen. Es wird dem Gravettien bzw. Périgordien zugewiesen. ${ }^{69}$ Beim von Morley als mögliche Pfeife mit Kerben an beiden Seiten angesprochenen Objekt aus SaintAvil-Sénieur (Dordogne) handelt es sich Neal zufolge eher nicht um eine Pfeife oder Flöte. ${ }^{70}$ Ebenfalls kein Musikinstrument sieht Neal in dem ungelochten $8 \mathrm{~cm}$ langen gravierten Vogelknochen aus Mammutova (Polen). Das Gleiche gilt für den Großteil der zwölf Knochenröhren (mit Ausnahme der zwei Objekte aus Vogelknochen und vielleicht einem Gämsenknochenfragment) aus dem Périgordien von Pekárna (Mähren). ${ }^{71}$ Ein weiteres Stück (14 cm lang), das nach Morley angeblasen den Ton „A“ produzierte, stammt aus dem Gravettien. ${ }^{72}$ Ein Fragment mit Fingerlöchern ist bei Turk und Kavur verzeichnet.

Aus dem Magdalénien in Frankreich sind zusätzliche Fundorte von Vogelknochen ohne Fingerlöcher bekannt: Fontarnaud in der Gironde, ein mögliches Flötenfragment aus Lussac (Vienne), zwei Fragmente aus Mas d'Azil (Ariège), vier Vogelknochenfragmente aus Raymonden sowie eine mögliche Flöte oder Pfeife aus Rond du Barry (Haute-Loire). Für das Magdalénien sind potentielle Funde von Pfeifen oder Flöten auch aus Spanien belegt: Cueva de Rascaño, Cueva de la Güelga und zwei Fragmente aus der Cueva del Castillo. Schließlich ist noch eine mögliche Hasenpfeife aus Padtberg bei Munzingen (Freiburg im Breisgau; Magdalénien) zu ergänzen. ${ }^{73}$

Generell ins Jungpaläolithikum fallen mögliche Fragmente von Pfeifen oder Flöten aus Arcy-sur-Cure (Yonne, Frankreich), aus Horodnica (Ukraine) und der Mammuthöhle bei Wizchowie in Polen, dem Kesslerloch in der

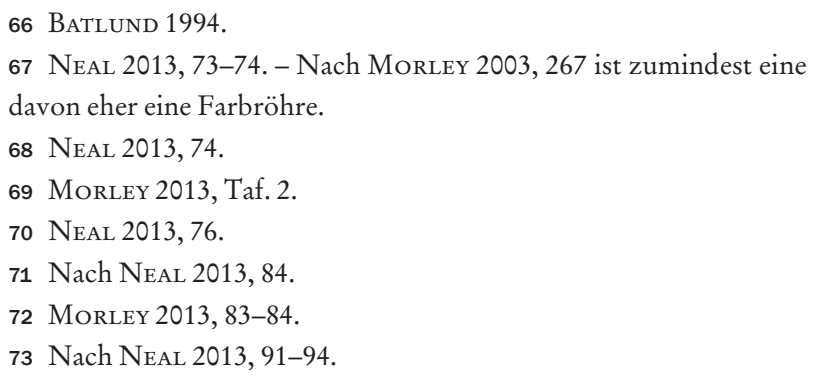


Schweiz (Schwanenknochen) und Csáklya in Ungarn. ${ }^{74}$ In Saint-Marcel (Indre, Frankreich) zieren zehn Cervidenohren, vermutlich Hirsch, eine Vogelknochenröhre. Es wäre möglich, dass ein Jagdinstrument zum Anlocken von Hirschkühen vorliegt. ${ }^{75}$ Bei einfachen ungedackten Röhren ist eine obertonbasierende Spielweise wie bei der rumänischen Tilincă möglich, die durch Anblasgeschwindigkeit und -kraft, sowie teilweises Abdecken am unteren Ende gesteuert wird. ${ }^{76}$

\subsection{Intentionell hergestellte Blasinstrumente}

Die Blasinstrumente der Fundstellen Vogelherd, Hohle Fels (Abb. 4/1) und Geißenklösterle (Abb. 4/2-3) stammen alle aus Aurignacien-Schichten und bestehen aus Schwanen-, Gänsegeier- bzw. unbestimmten Vogelknochen ${ }^{77}$ und aus Mammutelfenbein. ${ }^{78}$ Während die von Natur aus hohlen, mit Luft anstatt mit Knochenmark und Schwammgewebe gefüllten Röhrenknochen von Vögeln das ideale Ausgangsmaterial für die Herstellung von Blasinstrumenten sind, zeugt die Herstellung von Blasinstrumenten aus Elfenbein von einer darüber hinausgehenden handwerklichen Fertigkeit, da hier zwei Halbröhren geschnitzt und luftdicht zusammengefügt werden mussten. ${ }^{79}$ Conard et al. besprechen acht dieser Flöten aus der Region nahe der Donau im süddeutsch-schweizerischen Jura (bei Ulm).${ }^{80}$ Die Fundorte Geißenklösterle und Hohle Fels liegen ca. 3 km voneinander entfernt im Achtal, der Vogelherd liegt etwa $50 \mathrm{~km}$ weiter im Lonetal. Das früheste Datum für das Aurignacien in der Schwäbischen Alb liegt bei 43.000-41.000 vor heute. ${ }^{81} \mathrm{Als}$ Spieltechnik nehmen Susanne Münzel et al. vertikales oder schräges Randblasen an, wie es schon Friedrich Seeberger vorgeschlagen hat. ${ }^{82}$

Vom Aurignacien bis zum Magdalénien datieren Fragmente von ca. 20 separaten Flöten aus Isturitz. ${ }^{83}$ Dominique Buisson konnte zwei fast vollständige Exemplare rekonstruieren. ${ }^{84}$ D'Errico et al. untersuchten die komplette und die fast komplette Vier-Lochpfeife, die beide aus GravettienSchichten stammen, sowie die älteste gefundene Pfeife aus

74 Neal 2013, 96-97.

75 Allain 1950, 185. - Neal 2013, 137-138 und Abb. 4/20.

76 Nach NeAL 2013, 30.

77 Da Vogelknochen kein Knochenmark enthalten, sind Löcher an diesem Knochen höchstwahrscheinlich nicht auf Tierverbiss zurückzuführen.

78 Hahn, MünZel 1995.

79 Siehe CONARD et al. 2004, 455-456.

80 Conard, Malina, Münzel 2009, 739.

81 Siehe dazu Higham et al. 2012.

82 Münzel et al. 2016, 225, 231.

83 Buisson 1990.

84 Buisson 1994. dem Aurignacien (Abb. 4/6-8) mit optischen Mikroskopen und photometrischen Methoden. ${ }^{85}$ Die Spielweise war zweihändig und eher mit Rohrblatt- oder Trompeten-Anblastechnik denn als Flöte. Die Löcher bieten eine optimale Fingerauflage. Die Abweichung von der Achse um $5-15^{\circ}$ ist ebenfalls praktisch beim Spielen und wäre auch bei späteren Musiktraditionen üblich, besonders bei Rohrblatt- und lippengeblasenen (Horn, Trompete, Didgeridoo etc.) Instrumenten. ${ }^{86}$ Auf der Schwäbischen Alb wurde der Radius für die Blasinstrumente benutzt, in Isturitz wurde dagegen die Ulna bevorzugt.

Gilbert Fages und Cécile Mourer-Chauviré publizierten Zeichnungen von 24 vermeintlichen Aerophonen. Zeitlich werden Objekte von 26 Fundorten aus dem Périgordien (frühes und mittleres Jungpaläolithikum in Südwestfrankreich) (3), Aurignacien (6), Solutréen (2) und Magdalénien (4) sowie dem ausgehenden Paläolithikum (2) bis zum Mesolithikum (4) und Neolithikum (5) aufgelistet. ${ }^{87}$ Turk und Kavur zeigen neben dem Divje-babe-Fund neun weitere Relikte auf. ${ }^{88}$ Nach Jelle Atema lässt sich Les Roches bei Sergeac (Dordogne) dazuzählen. ${ }^{89}$ Einige potentielle Fundstücke aus der Literatur konnten noch nicht beurteilt werden und sind abschließend genannt.

Fages und Mourer-Chauviré erwähnen ein Vogelknochen-Fragment mit drei Löchern aus Pair-non-Pair (Abb. 4/4) in Marcamps (Gironde). Die Flöte datiert ins Frühpaläolithikum Südwestfrankreichs. ${ }^{90}$ Das Ende läuft schräg zu. Die Markierungen entsprechen technisch dem weiter unten beschriebenen Stil B des Verfassers (seichter und enger), verlaufen aber nicht nur typisch horizontal. Der Gesamteindruck deutet wiederum auf Überlegungen zur Melodieführung in grafischer Gestalt hin.

Ebenso dem Périgordien zugewiesen wird ein Vogelknochenfragment mit drei Löchern aus Abri Lespaux (Abb. 4/5) in Saint-Quentin-de-Baron (Gironde) mit Gruppen von Kerben zwischen zwei Löchern (Markierung C). ${ }^{91}$

Definitiv artifiziell ist ein Säugetierknochenfragment mit vier Löchern aus dem Magdalénien von Peyrat (Abb. 4/9) bei Terrasson-Lavilledieu (Dordogne). Fages und MourerChauviré denken an Querflötenspielweise.92

85 Lawson, D’Errico 2002. - D’Errico et al. 2003, 39-41 und Abb. 10-11.

86 D'Errico et al. 2003, 41-42.

87 Nach Fages, Mourer-Chauviré 1983.

88 Turk, Kavur 1997, Abb. 12.1.

89 Atema 2014.

90 Fages, Mourer-Chauviré 1983, 101 und Abb. 6/10.

91 Fages, Mourer-Chauviré 1983, 101 und Abb. 6/11.

92 Fages, Mourer-Chauviré 1983, 102 und Abb. 6/9. 


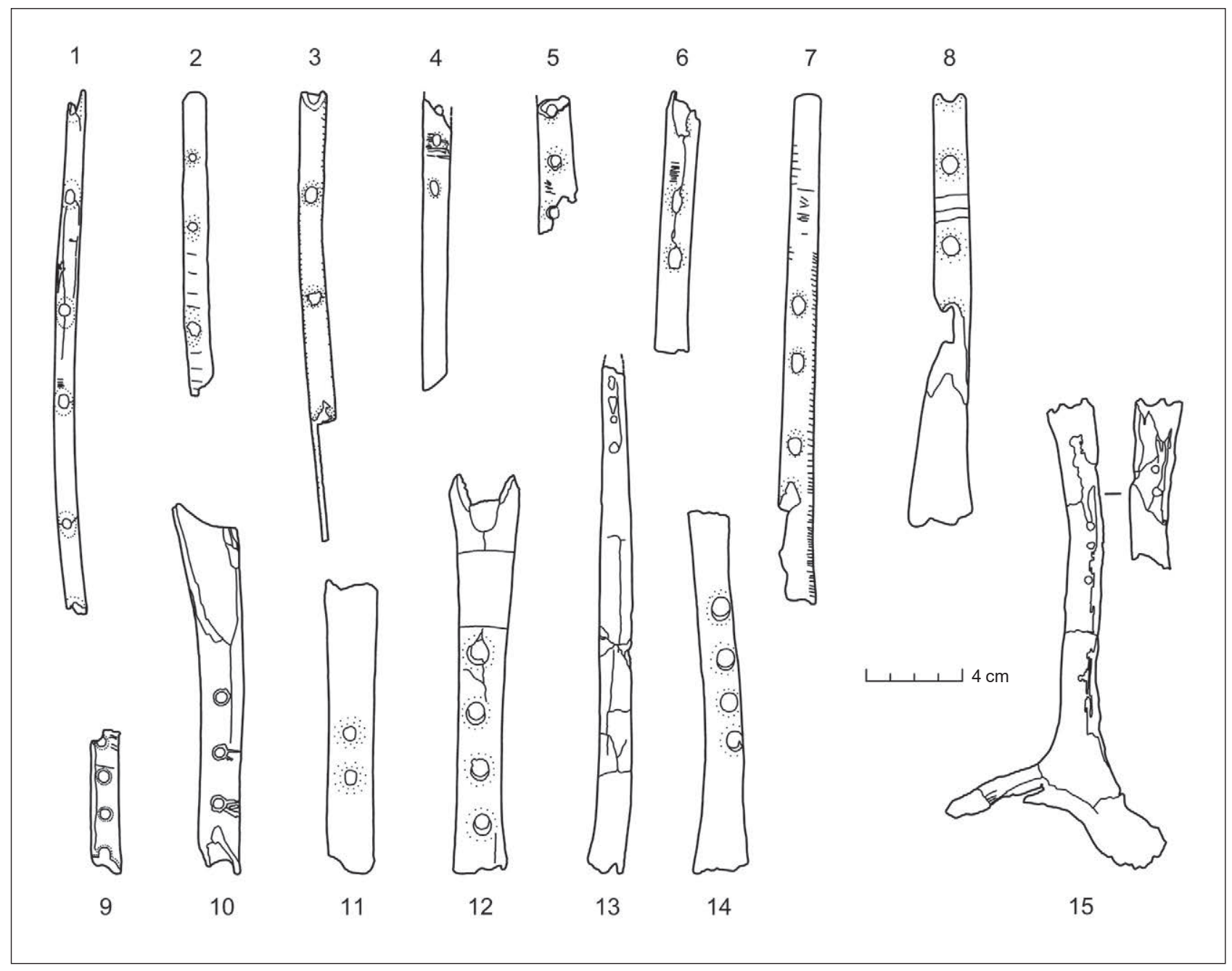

Abb. 4. Intentionell hergestellte Blasinstrumente des europäischen Jungpaläolithikums. - 1. Hohle Fels, Geier (nach MüNZEL et al. 2015, 31 und Abb. 3). - 2. Geißenklösterle, Schwan (nach MüNzel et al. 2015, 30 und Abb. 1). - 3. Geißenklösterle, Elfenbein (nach MüNZEL et al. 2015, 31 und Abb. 2). - 4. Pair-non-Pair, Vogel (nach Fages, Mourer-Chauviré 1983, 100). - 5. Abri Lespaux, Vogel (nach Fages, MourerChauviré 1983, 100). - 6. Isturitz, Geier (nach D’Errico et al. 2003, 41). - 7. Isturitz, Geier (nach D’Errico et al. 2003, 40). - 8. Isturitz, Geier (nach D’Errico et al. 2003, 40). - 9. Peyrat, Säugetier (nach Fages, Mourer-Chauviré 1983, 100). - 10. Kammern-Grubgraben, Huftier (nach Einwögerer, Käfer, Fladerer 1998, 23). - 11. Les Roches bei Sergeac (nach Atema 2014, 31 und Abb. 4A). - 12. Pas du Miroir, Vogel (nach Fages, Mourer-Chauviré 1983, 100). - 13. Moldova V, Geweih (nach Fages, Mourer-Chauviré 1983, 100). - 14. Moldova V, Geweih (nach Fages, Mourer-Chauviré 1983, 100). - 15. Moldova V, Geweih, Halbfabrikat (nach Lucius 1969-1970, 81 und Taf. XLII/6).

Die Menge der Blasinstrumente ist zwar bescheiden, doch die Verwendung von Säugetierknochen zeigt sich im Magdalénien an weiteren französischen Fundorten wie auch in Niederösterreich. Die 1994 in Grubgraben bei Kammern (Abb. 4/10) in Niederösterreich gefundene Knochenflöte ist aus der Tibia eines mittelgroßen Huftieres, etwa eines zweijährigen Rentieres, gefertigt. Es handelt sich um ein Fragment mit drei Löchern aus einer Schicht von 19.000 BP. Die Anblasvorrichtung ist nicht erhalten. ${ }^{93}$ Bernadette Käfer hat

93 EinwÖgerer, KäFer, Fladerer 1998, 21. dieses Blasinstrument auch experimentell untersucht und spielt es als Kerbflöte. ${ }^{94}$

Als eine der schönsten Magdalénien-Flöten bezeichnen Turk und Kavur ein Objekt aus Pas du Miroir (Abb. 4/12) mit vier vorderseitigen und zwei rückseitigen Löchern. Das Artefakt ist auch als Flöte von Abri Blanchard bekannt und wird weiters unter dem Fundortnamen La Roque bzw. La Roque Saint-Christophe (Dordogne) geführt. ${ }^{95} \mathrm{Als}$

94 KÄFER 1998, 102. - KNOCHENKLANG 2000.

95 Fages, Mourer-Chauviré 1983, Abb. 6/16. - Neal 2013, 78-79. 
Ausgangsmaterial wird bei Fages und Mourer-Chauviré Vogelknochen angegeben, ${ }^{96}$ während beispielsweise Atema Säugetierknochen nennt. ${ }^{97}$ Das eingekerbte Ende wird auf postmortalen Raubtierverbiss zurückgeführt. ${ }^{98}$ Atema zieht eine Anspielart wie bei der modernen Blockflöte in Betracht. ${ }^{99}$

Neal deutet ein aus Les Roches bei Sergeac stammendes Stück mit zwei Löchern als mögliche Querflöte (Abb. 4/11) und weist es dem Périgordien zu. ${ }^{100}$ Das Exemplar ist $123 \mathrm{~mm}$ lang und die Löcher befinden sich auf derselben Seite. ${ }^{101}$ Neal erwähnt weiters ein 11,5 cm langes Fragment mit zwei Fingerlöchern aus dem Magdalénien. ${ }^{102}$ Als Material dienten Säugetierknochen. Laut Atema ist die Spielweise nicht eindeutig zu eruieren. ${ }^{103}$

Eine vollständig erhaltene Querflöte könnte Alexander Häusler zufolge mit dem der Länge nach durchbohrten Geweih von der Station Moldova V (Abb. 4/13) am rechten Dnister-Ufer in der Ukraine vorliegen. ${ }^{104}$ Das Fundstück gehört Schicht IV (17.000 \pm 1400 BP) an. ${ }^{105}$ Es könnte unter Umständen mit der Nase angespielt worden sein und wird auch als Nasenflöte angesprochen. ${ }^{106}$ Die kleinen Dimensionen der Löcher lassen einige Forscher an der Interpretation als Flöte zweifeln. ${ }^{107}$ Nur weitere experimentelle Untersuchungen können Gewissheit geben.

Nach Turk und Kavur sowie Fages und Mourer-Chauviré wäre eine weitere Flöte aus Moldova V (Abb. 4/14) datiert auf $11.900 \pm 238$ oder $12.300 \pm 140 \mathrm{BP}-$ zu ergänzen. Das Artefakt weist vier Löcher auf der einen und zwei auf der anderen Seite auf. Auch diese Flöte besteht aus hohlem Hirschgeweih. ${ }^{108}$

Ein weiterer Fund aus der letzten jungpaläolithischen Schicht II ${ }^{109}$ der Fundstelle nahe dem heutigen Bratanivka,

96 Fages, Mourer-Chauviré 1983, 102.

97 Atema 2004, 19.

98 Turk, Kavur 1997, 183-184 und Abb. 12.1/10.

99 Atema 2004, 19. - Atema 2014, 31-32 und Abb. 4.

100 Neal 2013, 78.

101 Siehe auch https://www.britishmuseum.org/research/

collection_online/collection_object_details.aspx?objectId=342031

7\&partId=1\&searchText=Sturge.722.A (letzter Zugriff 21.8.2019).

102 NeAL 2013, 91.

103 ATEMA 2014, 31.

104 Häusler 1960. - Fages, Mourer-Chauviré 1983, Abb. 6/14. Lucius 1969-1970, 78 und Taf. XL/17.

105 Lucius 1969-1970, 78.

106 Holdermann 2001, 91.

107 Turk, Kavur 1997, 184.

108 Fages, Mourer-Chauviré 1983, 102 und Abb. 6/15. - Turk, Kavur 1997, 184 und Abb. 12.1/9.

109 Lucius 1969-1970, 81 und Taf. XLII/6.
Oblast Tscherniwzi, Ukraine (Abb. 4/15) könnte ein Halbfabrikat darstellen. Das Geweihinstrument ist in der Länge hohl (Durchmesser 1-2 mm). Es ist festzustellen, dass auch Geweih eine Spongiosa besitzt und natürlich hohl sein kann. Das Fundstück könnte im oberen Bereich der Löcher ausgebrochen und deshalb nicht fertiggestellt worden sein. Es sind drei bis sieben Löcher an der Vorder- und zwei an der Rückseite zu verzeichnen.

Bisher ungeklärt ist auch ein Hinweis auf eine Flöte aus Badegoule in Beauregard-de-Terrasson (Dordogne), zu der leider keine Abbildung vorliegt. Es handelt sich nach Fages und Mourer-Chauviré um eine Rentierspeiche mit drei Löchern. ${ }^{110}$

Abschließend seien noch einige mögliche Aerophone erwähnt, die Neal und Morley auflisten: Nach Neal seien in Badegoule vier Objekte aus dem Solutréen miteinzubeziehen. Neben dem dreifach gelochten Artefakt ist noch ein zweites Stück Rentierradius genannt. In Anlehnung an Scothern wird die Funktion als Musikinstrument in Frage gestellt. ${ }^{11}$ Cro-Magnon (Dordogne) ist ein weiterer fraglicher Flötenfundort. ${ }^{112}$ Ebenso bisher ungeklärt ist ein Exemplar aus dem Abri Laraux bei Lussac-les-Château (Vienne) mit einer Datierung 19.000 vor heute (Périgordien). ${ }^{113}$ Dem spanischen Solutréen zugerechnet wird eine zur Hälfte erhaltene Rentiertibia aus der La Riera-Höhle (ca. 16.900 BP); möglicherweise eine Blockpfeife. ${ }^{114}$ Ohne gesicherte $\mathrm{Da}$ tierung (wahrscheinlich Solutréen) liegt ein $8,3 \mathrm{~cm}$ langes Fragment mit zwei Löchern aus Liceia (Portugal) vor. ${ }^{115}$ Aus dem französischen Magdalénien sei Garrigue mit zwei eindeutig intentionell mit einem stichelartigen Werkzeug hergestellten Fingerlöchern genannt. ${ }^{116}$ Aus dem Magdalénien in Le Placard stammt neben den zahlreichen ungelochten Funden auch ein Fragment mit Anblasloch und zwei gestochenen (pierced) Fingerlöchern und einer Länge von $8,4 \mathrm{~cm} .{ }^{117}$ Schließlich sei noch ein Objekt aus Pekárna (Tschechien) zu nennen: ein Vogelknochen mit mehreren gesägten Löchern aus den Schichten G oder H mit Magdalénien-Funden. ${ }^{118}$

110 Fages, Mourer-Chauviré 1983, 101.

111 Scothern 1992. - Neal 2013, 85.

112 Neal 2013, 73-74 und Anm. 104.

113 Neal 2013, 79.

114 NeAL 2013, 86.

115 NEAL 2013, 86.

116 NeAL 2013, 87-88.

117 NeAL 2013, 89-90.

118 Turk, Kavur 1997, 184. 


\section{Markierungen}

Markierte Stäbe können als Kerb- oder Zählstöcke oder - wie die australischen message sticks - als Träger von Informationen gesehen werden. Auch einige nordamerikanische Ethnien verwenden gekerbte Botschaftsstäbe. Die verschlüsselte Information in Form geometrischer Motive ist für den Empfänger lesbar, was einer Art von Schrift nahekommt. ${ }^{119}$ Kurze und lange Markierungen könnten rhythmisch zu interpretieren sein, vielleicht Vogelrufe darstellen oder melodische Notation. In Frage käme auch eine Bindung für Rohrblätter, Federschmuck und Ähnliches. ${ }^{120}$ Nach Francesco d'Errico und Christopher Henshilwood sind die Markierungen auf zwei Instrumenten aus Isturitz sogar als musikalische Notation zu werten. ${ }^{121}$ Die Kerben könnten auch in Bezug zur Position der Grifflöcher auf den Instrumenten stehen, um entsprechende Intervalle und Tonfolgen $\mathrm{zu}$ erhalten (besonders Markierung A; siehe Tab. 2, Abb. 4).

Bisher konnten drei verschiedene Markierungsmuster festgemacht werden:

- Stil A: regelmäßige Kerben in über 1-2 mm breitem Abstand;

- Stil B: diffuser gesetzte Serien von Kerben, weniger tief, Abstände unter $1 \mathrm{~mm}$;

- Stil C: Gruppen von Kerben an einer bestimmten Stelle.

\section{Anbringung der Löcher}

Zur Ermittlung von Panflötenlängen sind nach Grauer die Verhältnisse 2/3 und 4/3 maßgebend. ${ }^{122}$ Nach Rolf Rottländer könnte man sich an überblasenen Tönen orientieren und so zu Harmonien im heutigen Sinn gelangen. ${ }^{123}$ $\mathrm{Zu}$ betonen ist, dass hier von der Annahme einer gleichwertigen Wahrnehmung oktavierter Töne ausgegangen wird. Mit den bereits angesprochenen Formeln zur Berechnung der Frequenzen von beidseitig offenen und einseitig geschlossenen Blasinstrumenten lassen sich auch die Frequenzen am obersten geöffneten Loch berechnen. Ein kleineres Loch ergibt kleinere Tonhöhensteigerung. ${ }^{124} \mathrm{Um}$ ein exaktes Ergebnis zu erhalten, ist auch noch die Mündungskorrektur $(\alpha)$ zur Rohrlänge zu addieren. Das Ende der Luftsäule liegt nicht genau in der Mündungsebene, sondern knapp dahinter. Die Mündungskorrektur ist abhängig von

119 Neal 2013, 25, 99-112. - Siehe auch Mithen 1996, 180.

120 Neal 2013, 130-135. - Siehe auch D’Errico et al. 2003.

121 D'Errico et al. 2003, 43-45. - D’Errico, Henshilwood 2011.

122 Grauer 2011, 213-215.

123 ROTTLÄNDER 1996, 36-38.

124 BENADE 1988. - WinKLER 1988. der Entfernung zum Rohrende und vom Radius des Rohres: $\alpha=$ s/R. ${ }^{25}$

Auch bei Fingerlöchern ist wie beim Rohrende ein teilweises Abdecken möglich, eine verkleinerte Lochgröße bewirkt einen tieferen Klang. Mit der Lochgröße ergibt sich auch die Möglichkeit einer Anpassung an die Reichweite der menschlichen Finger. ${ }^{126}$ Rechnet man die Abstände und Größen der Löcher in gleiche Größe und Entfernung um, lässt sich die Tonhöhe annähernd berechnen. ${ }^{127}$ Das Arbeiten mit Körpermaßen, z. B. Fingerlängen und -breiten, ist für das Bemessen der Löcher als sehr wahrscheinlich anzunehmen. ${ }^{128}$ Damals wie heute bedarf es dafür einer Menge an Feingefühl. Letzten Endes bestimmen aber physikalische Gesetze die klanglich optimale Ausgestaltung der Grifflöcher. $^{129}$

\section{Anblastechnik}

Für Flöten mit einem Durchmesser von bis zu $8 \mathrm{~mm}$ ist nach Seeberger eine ausgearbeitete Kante („Anschrägung der Lippenseite“) notwendig, um das Instrument als Flöte anspielen zu können. Es gilt, dass mit zunehmendem Durchmesser die Spielfähigkeit verbessert wird, weil die Kante weniger gekrümmt ist. Seeberger verweist auf Vergleiche aus Südamerika und Indien. ${ }^{130}$ Die Töne können wie bei einem bundlosen (fretless) Saiteninstrument im gesamten möglichen Spektrum variiert werden (glissando). ${ }^{131}$

Atema hat folgende Evolution der verschiedenen Flötentypen vorgeschlagen: offene Röhre (1a), geschlossene Röhre (1b), quer geblasene Pfeife (1c), offene Röhre mit V-Kerbe (2), mehrere gebündelte geschlossene Röhren (3), offene Röhre mit V-Kerbe und Fingerlöchern (wie die südamerikanische Quena oder die Ney) (4), geschlossenes quergeblasenes Rohr mit Fingerlöchern (Querflöte) (5), Kernspalt- oder Blockflöte (6), gebündelte offene Röhren mit Block (Orgel) (7) und geschlossene Gefäßflöte mit

125 Nach Auhagen 1994, 385-386. - Bei $\alpha=0,6$ (nach LotTermoser 1983 ) und $\mathrm{c}=344 \mathrm{~m} / \mathrm{s}$ ergibt sich für ein $1 \mathrm{~m}$ langes Rohr mit $1 \mathrm{~cm}$ Durchmesser eine Frequenz von $f_{1}=c /[2 \cdot(L+2 \alpha+R)]=170 \mathrm{~Hz}$; eine Vergrößerung des Rohrdurchmessers auf $3 \mathrm{~cm}$ bewirkt eine Absenkung der Grundfrequenz um $4 \mathrm{~Hz}$.

126 HALl 1997, 258-259.

127 Benade 1988, 29 und Abb. 8.

128 Darauf weisen besonders musikethnologische Studien hin: Ammann 2012, 70, 79.

129 Nach BenAdE 1988, 29.

130 Seeberger 1998, 31-33. - Seeberger 2002, 58 und Abb. der Kerb-, Schrägflöte.

131 Atema 2014, 27. - MünZel et al. 2015, 35-37. 
Fingerlöchern (Okarina) (8). ${ }^{132}$ Eine Deutung von V-Kerbflöten als Klarinetten, wie es beim Hohle Fels-Artefakt möglich ist, würde bedeuten, dass bereits vor dem Anbringen von Fingerlöchern das Einfachrohrblatt (Klarinette) und dann vielleicht auch das Mirliton bekannt gewesen sein könnten (Atema Gruppe 1).

Hein sieht keine Notwendigkeit eines Anblasens an einer Kante, da sich der Luftstrom an sorgfältig geschabten Löchern direkt an den Lochrändern bricht, ${ }^{133}$ was sich im Experiment gut bestätigen lässt. Die Abfolge, die das Anblasen von einer oberen Kante aus ergibt (sinkende Tonhöhe beim Verschließen des nächsten Loches), wird so aber nicht erzielt. Die Lautstärke ist ebenso geringer. Käfer zeigt dasselbe Prinzip auch für die Pfeife aus der Gudenushöhle (Niederösterreich), sie pfeift ohne Block. ${ }^{134}$

Die besten Ergebnisse für das Instrument aus Kammern-Grubgraben erzielt Käfer mit einer V-Kerbe zum Anspielen. Das Verwenden eines Blocks bezeichnet sie als die „aufwendigste Methode“ der Klangerzeugung. Sie räumt aber ein, dass eine Blockvorrichtung die einzige plausible Möglichkeit wäre, um das Instrument von der proximalen Seite her anzuspielen, wie es generell für Knochenflöten Usus wäre. ${ }^{135}$

Für die Kernspaltflöte ist ein Mundstück aus Bienenwachs und Holz- oder Knochenblättchen eine Möglichkeit. Einen Kern ganz aus Holz zu schnitzen wäre aufwendiger, die Mundstücke sind aber robuster und weniger anfällig auf Temperaturerwärmung. Auch könnte in prähistorischen Zeiten ein Loch in der Spongiosa am Knochenende den Luftstrahl in der Art eines Flötenblocks geleitet haben. Dazu gibt es Vergleiche bei Inuit und Yupik sowie bei den „First Nations“ Kanadas. ${ }^{136}$

Der wohl älteste eindeutige Beleg einer Block- beziehungsweise Kernspaltvorrichtung stammt aus Goyet in Belgien. ${ }^{137}$ Demnach ist auch das Fragment mit einem (labialen) Loch aus dem Maisières Kanal hier einzureihen (Périgordien; Flöte oder Pfeife nach Morley). ${ }^{138}$ Weiters sei hier auch auf das gravierte Vogelknochenartefakt aus Pekárna hingewiesen. ${ }^{139}$ Die Öffnung könnte mit Blocksystem

\footnotetext{
132 Atema 2014, 27 und Abb. 1.

133 HEIN 1998, 124.

134 KäFER 1998, 95 und Abb. 21.

135 KÄFER 1998, 108-111, 123-126.

136 Omerzel-Terlep 1997, 205.

137 Datiert zwischen 28.000 und 22.000 vor heute: NEAL 2013, 80.

- Morley 2013, Taf. 2. - Eine Abbildung findet sich bei TAmboer $1999,12$.

138 NeAL 2013, 80 .

139 Megaw 1960, 7 und Abb. 1/1.
}

angespielt worden sein. Aus Österreich ist diesbezüglich möglicherweise die genannte Pfeife aus der Gudenushöhle zu nennen. ${ }^{140}$ Weiters könnten Harzreste auf einer Röhre aus Dolní Věstonice einen eingesetzten Block andeuten. ${ }^{141}$ Das untere erhaltene Ende der $14 \mathrm{~cm}$ langen mit „zeichenartigem Strichwerk" versehenen Pfeife aus Le Placard ${ }^{142}$ würde sich als Klarinettenblattansatz eignen. Vielleicht haben wir hier ein bilaterales Instrument vorliegen - einerseits Blockpfeife, andererseits Rohrblattpfeife?

Neuerdings ist eine Pfeife in der Davant-Pau-Höhle im Nordosten der Iberischen Halbinsel entdeckt worden. Das 4,24 cm lange Objekt hat mittig ein schönes Labium und datiert auf ein Alter von 23.000 Jahren. ${ }^{143}$

\subsection{Einfachrohrblätter: „Steinzeitklarinette“}

Nach Jean-Loup Ringot ist das Blasinstrument aus der Hohle Fels-Höhle als eine Art Klarinette zu rekonstruieren. ${ }^{144}$ Es handelt sich um ein einfaches Rohrblattinstrument. Auf das abgeschrägte obere Ende kann ein Holzblättchen, vornehmlich aus Birkenrinde, gelegt und mit gewachster Hanfschnur festgebunden werden. Es ergeben sich ein mit modernen Klarinetten vergleichbares Mundstück und ein verzerrter, „entenartiger“ Klang. Der Nachbau erweist sich als relativ unkompliziert. Die Birkenrinde muss geschält oder geschliffen und ausgeschnitten werden.

Jean-Loup Ringot und Simon Wyatt ${ }^{145}$ erzielten über das Zusammenkleben mehrerer Vogelknochen eine größere Instrumentenlänge. Abgebildet sind Verbindungen mit Bienenwachs (und einer Hornmuffe?). Der Verfasser probierte das Kleben mit Birkenteer und verwendete wie Ringot und Wyatt Horn (Gämsen- bzw. Rinderhorn) für das Rohrblatt. Zu den umfassenden Versuchen von Friederike Potengowski ${ }^{146}$ ergänzen Ringot und Wyatt die Möglichkeit von Rohrblättern als Mundstücke. Wyatt ${ }^{147}$ zeigt aber unter anderem auch sechs Möglichkeiten, das Hohle FelsInstrument als Flöte anzuspielen.

Die bisherigen Tonaufnahmen, die inzwischen mit LARA (Luzerne Audio Recording Analyzer) durchgeführt werden, zeigen einige Besonderheiten auf. Am wichtigsten

140 KÄFER 1998, 95 und Abb. 21. - Ob die Pfeife ins Magdalénien oder in die Bronzezeit datiert, ist nach SEEWALD 1934, 41-42 und Taf. II/10 nicht klar.

141 NeAL 2013, 31-32.

142 Seewald 1934, 41 und Taf. II/7-8.

143 IвÁÑEZ et al. 2015.

144 Ringot 2011. - Ringot 2012.

145 WYATT 2012. - WYATT 2016.

146 Z. B. MÜNZEL et al. 2015. - MÜNZEL et al. 2016.

147 WYATT 2016, 210. 
ist die Tatsache, dass ein Instrument in den Dimensionen der vollständig rekonstruierten Hohle Fels-Klarinette (ca. $32 \times 8 \mathrm{~mm}$ ) als Rohrblattinstrument genau den Ambitus einer Oktave aufweist (komplett geschlossen bis zum obersten Fingerloch). Seeberger merkte bezüglich Flöteninstrumenten an, dass ab $8 \mathrm{~mm}$ Durchmesser und darüber bessere Ergebnisse als randgeblasene Flöte zu erzielen sind. Genau unter diesem kritischen Durchmesser sind die Speichenknochen von der Schwäbischen Alb. Tatsächlich sind die Versuche des Verfassers, Instrumente in dieser Dimension als Flöten zu spielen, wenig erfolgreich. Auch der geübte Schrägflötist Thomas Olesch kann die unteren Löcher der Hohle Fels-Flöte nur durch Überblasen zum Klingen bringen. ${ }^{148}$ Ein Geschenk von Ringot, das exakt dem Instrument aus Isturitz (Abb. 4/7) nachempfunden ist, sticht in den Analysen zunächst dadurch hervor, dass die doppelte Frequenz vom tiefsten bis zum höchsten Ton erklingt (wieder die Oktave), wenn in vertikaler Flötentechnik angeblasen wird. Das oberste Loch geöffnet und alle unteren geschlossen, ergibt als Schrägflöte überblasen die Oktave.

Die französischen jungpaläolithischen Aerophone haben bemerkenswert größere Durchmesser und die Löcher beginnen weiter unten am Instrument, was ein Spielen als Flöten erleichtert. Ein ideoglottes Mundstück lässt sich aber auch leicht an dem Isturitz-Nachbau anbringen und ermöglicht den Tonumfang einer Quinte.

Dass die Töne in Ganz- und Eineinhalbtonschritte fallen, leitet sich aus den Röhrengesamtlängen und den Abständen der menschlichen Finger ab. Damit ergeben sich sehr leicht Töne, die pentatonischen Skalen entsprechen. Es ist jedoch Vorsicht geboten, da eine Tonleiter nur unsere moderne Ansicht von Melodik widerspiegelt. Vielmehr scheinen bestimmte musikalische Themen und Riffs aus den Instrumenten heraus zu kommen, die zukünftig ausgearbeitet werden sollen, um den ursprünglichen Liedern näher zu kommen. ${ }^{149}$

Münzel et al. gehen für die Hohle Fels-Flöte von Anblastechniken ohne Mundstück aus. ${ }^{150}$ Zunächst wird direkt hindurch geblasen, was aufgrund der flach geschnitzten Löcher (eher leise) fünf Töne $\left(\mathrm{a}^{3}, \mathrm{~b}^{3}, \mathrm{c}^{4}, \mathrm{e}^{4}, \mathrm{f}^{4}\right)$ ergibt. Als Schrägflöte ohne Kerbe (gespielt wie die Ney oder Hirtenflöten aus dem Mittelmeerraum) werden ohne Gabelgriff-Kombinationen sieben Töne $\left(c^{3}, d^{3}, f^{3}, b^{3}\right.$ und $\left.c^{4}, d^{4}, f^{4}\right)$ erzielt. Die Elfenbeinbeinflöte vom Geißenklösterle wurde mit derselben Technik von der Seite, an der nur der Steg erhalten ist, angespielt und um $23 \mathrm{~mm}$ verlängert. Es ergaben sich acht „wohlklingende Intervalle“ $\left(\mathrm{f}^{2}, \mathrm{~g}^{2}, \mathrm{~h}^{2}, \mathrm{dis}^{3}, \mathrm{e}^{3}, \mathrm{fis}^{3}, \mathrm{~h}^{3}\right.$,

148 Freundliche Mitteilung Thomas Olesch.

149 Ammann, Praxmarer im Druck.

150 Münzel, Conard 2009. - MÜnZel et al. 2016. dis ${ }^{4}$ ). Im Jahr 2016 präsentierte Potengowski zehn mögliche technische Spielvarianten, z. B. Triller, Vibrato, gleichzeitiges Singen und mehrere sich überlagernde Klänge, inklusive der entsprechenden Hörbeispiele. ${ }^{151}$ Für Neal spielt die Replik vom Geißenklösterle anhemitonische Pentatonik (ohne Halbtonschritte) und diatonische Melodien. ${ }^{152}$ Ihrer Ansicht nach ist auch mit dem Vier-Loch-Instrument, das Buisson nach dem Fund aus Isturitz rekonstruierte, das Spielen einer pentatonischen Skala möglich. ${ }^{153}$

\subsection{Einfachrohrblätter: „Steinzeitschalmei“}

Eine weitere Anblastechnik, die sich mit den sardischen Launeddas vergleichen lässt, schlagen Ringot und Wyatt vor: Am Ende eines Federkiels wird ein Schnitt angebracht und mit einem dünnen Faden aufgespreizt, wodurch der obere Teil beim Anblasen schwingt. Dasselbe funktioniert mit Holzrohr- und Knochenaufsätzen. ${ }^{154}$ Ein mit dem Finger gespaltener Grashalm ermöglicht es, „dünne Knochenflöten kinderleicht als Rohrblattinstrument zu spielen“. ${ }^{155}$ In Sachs' „Geschichte der Musikinstrumente“ ist neben dem gespaltenen Grashalm auch ein gewickeltes Grasblatt als Einfachrohrblatt überliefert. ${ }^{156}$ Die Beispiele mit geradem Abschluss könnten derartig zu interpretieren sein.

Ebenso wie das Klarinettenmundstück ist die „Steinzeitschalmei“ mit dem Launedda-Mundstück einfacher herzustellen als Kernspaltflöten. Technisch liegt ein idioglottes Klarinetteninstrument vor. ${ }^{157}$

151 MÜNZEL et al. 2016, 233.

152 NEAL 2013, 70.

153 Neal 2013, 81 und Anm. 110.

154 WYATT 2012.

155 KERIG 2009, 328.

156 SACHs 1940, 38 und Abb. 12-13.

157 Z. B. Pomberger 2016, 24. - Im Jahr 2011 hat das MIMO Konsortium (Musical Instruments Museum Online, http:// www.mimo-international.com) die Typologie von Hornbostel und Sachs neu überarbeitet. Dabei gibt es Neuzugänge in der Schalmeien-Kategorie. Aus Oboen (422.1), Klarinetten (422.2) und Durchschlagzungen-Schalmeien (422.3) der alten Terminologie (HoRnbostel, SACHs 1914, 587-588) werden nun in der Rohrblätter (Reedpipes) genannten Kategorie Doppel- oder Vierfachrohrblätter (422.1), Einfachrohrblätter (422.2) und Rohrblätter mit einem Blatt, das durch einen Rahmen vibriert (422.3). In letzterer Kategorie werden einfache oder doppelte Ausführung oder auch Hörner mit freiem Rohrblatt wie in Burma mit einberechnet. Weiters kommt die Gruppe der Dilating Reeds (oder „weitere Rohrblätter“) hinzu (422.4). Dazu zählen Grasstängel und Ähnliches, bei denen ein gerader Schlitz angebracht wird. Der Rohrblattbereich wird mit dem ganzen Mund erfasst. Als Beispiel eines Objekts mit Fingerlöchern wird bei MIMO auf die Fadno, das einzige traditionelle Melodieinstrument der Samen, verwiesen: Mimo 2011, 2, 19-20. - Zur Fadno siehe auch EMSHEIMER 1947. 


\subsection{Mirlitons: die „Verzerrer der Steinzeit“}

Ansingtrommeln oder Mirlitons ${ }^{158}$ sind röhrenförmige Vogelknochen oder perforierte Scheiben (z. B. aus Stein, Knochen oder Holz) bei denen eine mitschwingende Membran beim Anblasen eine Klangverzerrung der Stimme bewirkt. ${ }^{159}$ Auch Röhren mit nur einem kleinen Loch können, mit Membran versehen, zum Verzerren der Stimme beitragen. Auch mehrere Löcher sind möglich. Genauso können die Membranen am Ende angebracht werden. Beim Sprechen und Singen schwingt die Membran und ändert die Klangfarbe der Töne. Aus Le Placard I stammt ein schmales Röhrchen mit einem endständigen Loch. Seewald sah darin eine Anhängevorrichtung. ${ }^{160}$ Es wäre gut tauglich als Stimmenverzerrer.

$\mathrm{Ab}$ welcher Zeitperiode Stimmenverzerrer eingesetzt wurden, lässt sich noch nicht sagen. Die Steinzeitklarinetten, die Ringot für die Schwäbische Alb rekonstruierte, baute er auch als Mirlitons nach - mit einer Membran am obersten Loch. ${ }^{161}$ In unseren Experimenten ist auch dies einfach zu bewerkstelligen: Ein Stück Naturdarm wird bis über das Loch geschoben, oben festgebunden und getrocknet. Darmhaut ist einer der Rohstoffe, die im harschen pleistozänen Klima relativ gut verfügbar sind; tierische Materialien stehen im Eis an erster Stelle. Als Membranmaterial können neben dünnen Tierhäuten auch Eierhaut oder Spinnenkokone dienen. Von den Dan im nördlichen Grenzgebiet der Elfenbeinküste sind Mirlitons in Form von Vogelknochen überliefert, die mit einem „Spinnengespinst“ verschlossenen sind. Sie werden zum „Verstärken und Verändern der Stimme“ und „deshalb häufig bei Kulthandlungen verwendet“. 162

\section{Schlussbemerkungen}

Mit dem europäischen Jungpaläolithikum fassen wir nicht nur mythische Abbildungen, plastischen Schmuck und figürliche Kunst, sondern auch die ersten Funde von

158 Klasse 24 nach der Systematik von Hornbostel, SACHS 1914, 578. Hornbostel und Sachs unterscheiden Freie Mirlitons (241) (z. B. Seidenpapier auf dem Kamm) von Röhren und Gefäßmirlitons (242). Die Neufassung der Hornbostel und Sachs-Typologie von 1914 durch das MIMO Konsortium enthält in der Kategorie Unterbrechungsaerophone und Rohrblätter zusätzlich die Kategorie der Retreating Reeds, das sind natürlich oder künstlich zusammengeschnürte Elemente, die sich periodisch separieren, wenn sie angeblasen werden: Мiмо 2011, 6.

159 Neal 2013, 38-42. - Siehe dazu Balfour, Blackwood 1948, bes. 46 .

160 SeEwald 1934, 40 und Taf. II/9.

161 Ringot 2012, Abb. 3.

162 Meyer 1977, 35-36.
Musikinstrumenten. Die vielfältige Zusammensetzung der Gesellschaft verlangte wahrscheinlich nach komplexeren Kommunikationsformen. Musik hilft, Bewegungen zu synchronisieren, fördert das soziale Leben und dient der Kommunikation. Die ersten Musikinstrumente machen diese Vorgänge kulturell greifbar. Mit dem hier aufgezeigten Korpus der intentionell hergestellten Blasinstrumente liegen hervorragende Versuchsobjekte vor, die in zukünftigen Studien genau untersucht werden sollen, um mehr über deren mögliche Funktionen und die am besten spielbaren Abfolgen und Lieder herauszufinden.

Im jungpaläolithischen Kontext stand wahrscheinlich besonders die Vorbereitung und Durchführung der Jagd im Vordergrund. Langflöten bzw. Einfachrohrblättern mit mehreren Löchern, die die ersten Melodieinstrumente der Menschheit sind, kam dabei wahrscheinlich eine wichtige Funktion zu. Das Darstellen einer fiktiven mythologischen Figur mit einer musikalischen Figur auf einem Instrument erweitert die Erzählkultur und macht die SpielerInnen zu SpezialistInnen für das Kombinieren von Tönen - und damit auch für das Kontrollieren von Emotionen sowie das Fördern der Gesundheit und der Identität der Gruppe.

Welche Auswirkungen die Entwicklung stabiler Intervalle und abrufbarer Tonfolgen auf die Entwicklung der kognitiven Fähigkeiten hatte, ob im Austauschen über den Aufbau der Musik der Ursprung analytischen Denkens zu suchen ist oder ob Körpermaße und gekerbte Objekte eingesetzt wurden, um erwünschte Intervalle zu erzielen, und damit Physik und Mathematik angewandt wurden, ${ }^{163}$ wird die zukünftige Forschung klären.

Jedenfalls sehen wir mit den ersten Melodieinstrumenten weitere künstlerische Aktivitäten initiiert, die sich über 30.000 Jahre fortsetzen. Die Anfänge von musikalischem Verhalten sind sehr weit in der Evolution zurückverfolgbar. ${ }^{164}$ Zumindest ab dem aufrechten Gang wäre es denkbar, dass fallweise eine Tendenz zu gesangsähnlichem Sprachstil vorherrschend war. Die Verwendung von Klanggeräten bei der Jagd spielt bestimmt eine wichtige Rolle. Mit den Blasinstrumenten des Aurignacien stehen wir bereits hochentwickelten Traditionen gegenüber. Nach derzeitigem Forschungsstand fassen wir jedoch erst hier materielle Zeugnisse, die allen Anforderungen von Musikinstrumenten im heutigen Sinn entsprechen.

163 D’Errico et al. 2003. - Killin 2018. - FeliKs 2011 erkennt am Geißenklösterle-Aerophon Hinweise auf Kenntnis und Nutzung von $\phi$, dem goldenen Schnitt. - Zum Zusammenhang zwischen Sprache und Musik siehe auch Brown 2000. - KunEJ, Turk 2000. Mithen 2005.

164 Mithen 2005. - Tomlinson 2015. - Killin 2018. 
Tab. 1. Liste der Musikinstrumente des europäischen Jungpaläolithikums (Blasinstrumente ausgenommen).

\begin{tabular}{|c|c|c|c|c|}
\hline Typus & Fundort & Datierung & Anmerkungen & Literatur \\
\hline Schwirrholz & Tata (Ungarn) & $\begin{array}{l}\text { mögliches Exemplar aus } \\
\text { dem Mittelpaläolithikum }\end{array}$ & Elfenbeinlamelle? & ZaGiba 1976, Abb. $1 / 2$. \\
\hline Schwirrholz & Vogelherd (Deutschland) & Aurignacien & Elfenbein & Holdermann 2001, 92. \\
\hline Schwirrholz & $\begin{array}{l}\text { Ahrensburg-Stellmoor } \\
\text { (Deutschland) }\end{array}$ & Oberes Jungpaläolithikum & Rentierknochen & KeRIg 2009, 329. \\
\hline Schwirrholz & $\begin{array}{l}\text { Roche de Birol bei Lalinde } \\
\text { (Frankreich) }\end{array}$ & Magdalénien & verziertes Rentiergeweih & SEEwald 1934, 14 und Taf. I. \\
\hline Schwirrholz & $\begin{array}{l}\text { Abri du Bois de la Garenne, } \\
\text { Saint-Marcel (Frankreich) }\end{array}$ & Magdalénien & verziert & SEEWALD 1934,14 und Taf. I/6a-b. \\
\hline Schwirrholz & $\begin{array}{l}\text { Laugerie-Basse, Eyzies-de- } \\
\text { Tayac (Frankreich) }\end{array}$ & Magdalénien & verziert & SEEwald 1934, 14 und Taf. I/7. \\
\hline Schwirrholz & $\begin{array}{l}\text { Grotte des Harpons, } \\
\text { Lespugue (Frankreich) }\end{array}$ & Obere Solutréen-Schichten & & SEEWALD $1934,14$. \\
\hline Schwirrholz & $\begin{array}{l}\text { Grotte de Badegoule, } \\
\text { Beauregard-de-Terrasson } \\
\text { (Frankreich) }\end{array}$ & Solutréen & verziert & Morley 2003, 33-36 und Abb. 3.2. \\
\hline Schwirrholz & $\begin{array}{l}\text { Fontalès, Saint-Antonin- } \\
\text { Noble-Val (Frankreich) }\end{array}$ & Spätes Magdalénien & verziert? & Morley 2003, 35. \\
\hline Schwirrholz & $\begin{array}{l}\text { Abri Morin, Pessac-sur- } \\
\text { Dordogne (Frankreich) }\end{array}$ & Spätes Magdalénien & $\begin{array}{l}\text { gravierte Boviden auf } \\
\text { beiden Seiten }\end{array}$ & Morley 2003, 35. \\
\hline Schwirrholz & $\begin{array}{l}\text { Grotte de Lortet } \\
\text { (Frankreich) }\end{array}$ & Spätes Magdalénien & $\begin{array}{l}\text { gravierte Boviden auf } \\
\text { beiden Seiten }\end{array}$ & Morley 2003, 35. \\
\hline Schraper & Schulen (Belgien) & $50.000 / 40.000$ vor heute & $\begin{array}{l}\text { umstritten, weil aus } \\
\text { Neandertaler-Kontext / } \\
\text { Tierverbiss möglich }\end{array}$ & Morley 2003, 37. \\
\hline Schraper & $\begin{array}{l}\text { Grotte Vaufrey, Cénac-et- } \\
\text { Saint-Julien (Frankreich) }\end{array}$ & Mittelpaläolithikum & $\begin{array}{l}\text { unsicher, da Tierverbiss } \\
\text { möglich }\end{array}$ & Morley 2003, Abb. 3.4. \\
\hline Schraper & Cro-Magnon (Frankreich) & Aurignacien & Schrapknochen & $\begin{array}{l}\text { SEEWALd 1934, 12. - HoldermanN } \\
2001,90 .\end{array}$ \\
\hline Schraper & $\begin{array}{l}\text { Geißenklösterle } \\
\text { (Deutschland) }\end{array}$ & Aurignacien & $\begin{array}{l}\text { bandförmiges } \\
\text { Geweihstäbchen }\end{array}$ & Holdermann 2001, 90. \\
\hline Schraper & Brillenhöhle (Deutschland) & Magdalénien & gekerbter Elfenbeinstab & Holdermann 2001, 90. \\
\hline Schraper & $\begin{array}{l}\text { Dolní Věstonice } \\
\text { (Tschechien) }\end{array}$ & Magdalénien & $\begin{array}{l}\text { Wolfsknochen mit klar } \\
\text { geschnittenen Riefen }\end{array}$ & Holdermann 2001, 90. \\
\hline Schraper & Pekárna (Tschechien) & Magdalénien & $\begin{array}{l}\text { gekerbter Lochstab aus } \\
\text { Rentiergeweih }\end{array}$ & $\begin{array}{l}\text { Zagiba 1976, 14. - SEewald } 1934 \text {, } \\
\text { 12. - Morley 2003, Abb. 3.4. }\end{array}$ \\
\hline Schraper & $\begin{array}{l}\text { Laugerie-Basse, Les Eyzies } \\
\text { (Frankreich) }\end{array}$ & Magdalénien & $\begin{array}{l}\text { auf beiden Seiten } \\
\text { eingekerbter Knochen } \\
\text { (mit Lochstabaffinität) }\end{array}$ & SeEwald 1934, 12 und Taf. I, 2a-b. \\
\hline Schraper & $\begin{array}{l}\text { Laugerie-Haute, Les Eyzies } \\
\text { (Frankreich) }\end{array}$ & Magdalénien & $?$ & SEEWALD $1934,12$. \\
\hline Schraper & $\begin{array}{l}\text { La Madeleine, Tursac } \\
\text { (Frankreich) }\end{array}$ & Magdalénien & $?$ & SEEWALD $1934,12$. \\
\hline Schraper & $\begin{array}{l}\text { Abri du Château bei } \\
\text { Bruniquel (Frankreich) }\end{array}$ & Magdalénien & gekerbter (?) Knochen & $\begin{array}{l}\text { SeEWALd 1934, 12. - MoRley 2003, } \\
\text { Abb. 3.4. }\end{array}$ \\
\hline
\end{tabular}


Tab. 1. Fortsetzung.

\begin{tabular}{|l|l|l|l|l|}
\hline Typus & Fundort & Datierung & Anmerkungen & Literatur \\
\hline Schraper & Mas d'Azil (Frankreich) & Spätes Jungpaläolithikum & gekerbter Lochstab & $\begin{array}{l}\text { SEEWALD 1934, 12. - MORLEY 2003, } \\
\text { Abb. 3.4. }\end{array}$ \\
\hline Schraper & La Riera-Höhle (Spanien) & $\begin{array}{l}\text { Schichtdatum } \\
19.000-18.310 \pm 260 \mathrm{BP}\end{array}$ & gravierte Rippe & MoRLEY 2003, 39. \\
\hline Schlagzeug & Brillenhöhle (Deutschland) & Magdalénien & T-Trommelschlegel & HoLDERMANN 2001, 90-91. \\
\hline Schlagzeug & Mezin (Ukraine) & 20.000 vor heute & $\begin{array}{l}\text { Hüft-, Schädel-, } \\
\text { Schulterblatt- und } \\
\text { Kieferknochen von mehr } \\
\text { als einem Mammut; alle } \\
\text { Skeletteile mit Okker } \\
\text { bemalt; Schlagspuren (!) }\end{array}$ & DAMs 1985, 44. \\
\hline Musikbogen & $\begin{array}{l}\text { Geißenklösterle } \\
\text { (Deutschland) }\end{array}$ & Aurignacien & $\begin{array}{l}\text { verziertes Geweihband } \\
\text { mit gelochten Enden; } \\
\text { aus unmittelbarer Nähe } \\
\text { der Flötenfunde? }\end{array}$ & KERIG 2009, 329 und Abb. 404. \\
\hline Musikbogen & $\begin{array}{l}\text { Solutré-Pouilly } \\
\text { (Frankreich) }\end{array}$ & 22.000-18.000 vor heute & $\begin{array}{l}\text { mit 53 Schnitten } \\
\text { gravierte Nashorn- } \\
\text { Rippe? }\end{array}$ & $\begin{array}{l}\text { D’ERRICO et al. 2003, 34 und } \\
\text { Abb. 8a. }\end{array}$ \\
\hline
\end{tabular}

Tab. 2. Liste der intentionell hergestellten Blasinstrumente des europäischen Jungpaläolithikums. - L: Erhaltene Länge in cm. - Dm: Durchmesser in cm. - M: Markierungen (A, B, C, -).

\begin{tabular}{|c|c|c|c|c|c|c|}
\hline Fundort & Datierung & $\mathrm{L}$ & $\mathrm{Dm}$ & Anmerkungen & M & Nachweis \\
\hline $\begin{array}{l}\text { Vogelherd } \\
\text { (Deutschland) }\end{array}$ & Aurignacien & $?$ & $?$ & $\begin{array}{l}3 \text { Fragmente Vogelknochen, } \\
1 \text { Fragment Mammutelfenbein } \\
\text { (verziert) }\end{array}$ & A & $\begin{array}{l}\text { Hahn, Münzel 1995. - } \\
\text { Conard, Malina, Münzel } \\
2009 .\end{array}$ \\
\hline $\begin{array}{l}\text { Hohle Fels } \\
\text { (Deutschland) } \\
\text { Blasinstrument } 1 \\
\text { (Abb. 4/1) }\end{array}$ & Aurignacien & 21,8 & 0,8 & $\begin{array}{l}\text { Geierknochen-Speiche mit Resten } \\
\text { von } 5 \text { Löchern und spitzkonischem } \\
\text { Ende }\end{array}$ & $\mathrm{C}$ & $\begin{array}{l}\text { Conard, Malina, Münzel } \\
\text { 2009. - Münzel et al. } 2015 .\end{array}$ \\
\hline $\begin{array}{l}\text { Blasinstrumente } \\
2 \text { und } 3\end{array}$ & Aurignacien & $?$ & $?$ & 2 Fragmente von Elfenbeinflöten & A & $\begin{array}{l}\text { Conard, Malina, Münzel } \\
2009 .\end{array}$ \\
\hline $\begin{array}{l}\text { Geißenklösterle } \\
\text { (Deutschland) } \\
\text { Blasinstrument } 1 \\
\text { (Abb. 4/2) }\end{array}$ & Aurignacien & 12,65 & $\begin{array}{c}1,03- \\
0,81\end{array}$ & $\begin{array}{l}\text { Schwanen-Speiche mit } 3 \text { oder } 4 \\
\text { erhaltenen Löchern }\end{array}$ & A & $\begin{array}{l}\text { Hahn, Münzel 1995. - } \\
\text { Conard, Malina, Münzel } \\
\text { 2009. - Ringot } 2012 .\end{array}$ \\
\hline $\begin{array}{l}\text { Blasinstrument } 2 \\
(\text { Abb. } 4 / 3)\end{array}$ & Aurignacien & 18,7 & 0,95 & $\begin{array}{l}\text { Mammutelfenbein mit } 3 \text { (oder } 4 \text { ) } \\
\text { erhaltenen Löchern }\end{array}$ & A & $\begin{array}{l}\text { Hahn, Münzel 1995. - } \\
\text { Conard, Malina, MünZel } \\
\text { 2009. - MüNZel et al. } 2015 .\end{array}$ \\
\hline Blasinstrument 3 & Aurignacien & $?$ & $?$ & $\begin{array}{l}\text { Vogelknochen in Schwanengröße in } \\
7 \text { Fragmenten }\end{array}$ & & $\begin{array}{l}\text { Conard, Malina, Münzel } \\
2009 .\end{array}$ \\
\hline $\begin{array}{l}\text { Pair-non-Pair } \\
\text { (Frankreich) } \\
\text { (Abb. 4/4) }\end{array}$ & $\begin{array}{l}\text { Périgordien } \\
\text { (ca. 38.000-21.000 } \\
\text { vor heute) }\end{array}$ & 12,1 & $1,05-1,2$ & $\begin{array}{l}\text { Vogelknochen; } 2 \text { vollständige } \\
\text { und } 1 \text { teilweise erhaltenes Loch; } \\
\text { spitzkonisches Ende }\end{array}$ & $\mathrm{C}$ & $\begin{array}{l}\text { Fages, Mourer-Chauviré } \\
1983 .\end{array}$ \\
\hline
\end{tabular}


Tab. 2. Fortsetzung.

\begin{tabular}{|c|c|c|c|c|c|c|}
\hline Fundort & Datierung & $\mathrm{L}$ & Dm & Anmerkungen & $\mathbf{M}$ & Nachweis \\
\hline $\begin{array}{l}\text { Abri Lespaux, } \\
\text { Saint-Quentin- } \\
\text { de-Baron } \\
\text { (Frankreich) } \\
\text { (Abb. 4/5) }\end{array}$ & Périgordien & 5,8 & $1,1-1,6$ & $\begin{array}{l}\text { Vogelknochen; } 1 \text { vollständiges und } \\
2 \text { teilweise erhaltene Löcher }\end{array}$ & $\mathrm{C}$ & $\begin{array}{l}\text { Fages, Mourer-Chauviré } \\
1983 .\end{array}$ \\
\hline $\begin{array}{l}\text { Isturitz } \\
\text { (Frankreich) } \\
\text { Blasinstrument } 1 \\
\text { (Abb. 4/6) }\end{array}$ & Aurignacien & 10,9 & $0,7-0,8$ & $\begin{array}{l}\text { Mönchsgeier-Elle mit } 2 \text { oder } 3 \\
\text { erhaltenen Löchern }\end{array}$ & $\mathrm{C}$ & $\begin{array}{l}\text { Buisson 1994. - D'ERrico et } \\
\text { al. } 2003 .\end{array}$ \\
\hline $\begin{array}{l}\text { Blasinstrument } 2 \\
\text { (Abb. 4/7) }\end{array}$ & Gravettien & 21,2 & $1-1,6$ & $\begin{array}{l}\text { Mönchsgeier-Elle; komplett mit } 4 \\
\text { Löchern und gerader Endkante }\end{array}$ & B & $\begin{array}{l}\text { Buisson 1994. - D'ERrico et } \\
\text { al. } 2003 .\end{array}$ \\
\hline $\begin{array}{l}\text { Blasinstrument } 3 \\
\text { (Abb. } 4 / 8)\end{array}$ & Gravettien & 18,1 & $1,3-2,6$ & $\begin{array}{l}\text { Mönchsgeier-Elle; fast komplett mit } \\
4 \text { Löchern und gerader Endkante }\end{array}$ & B & $\begin{array}{l}\text { BuISSON 1994. - D'ERrico et } \\
\text { al. } 2003 .\end{array}$ \\
\hline $\begin{array}{l}\text { Insgesamt } \\
\text { Fragmente von } \\
\text { mehr als } 20 \\
\text { Blasinstrumenten }\end{array}$ & $\begin{array}{l}\text { Aurignacien bis } \\
\text { Magdalénien }\end{array}$ & - & - & Mönchsgeier & $\begin{array}{l}\mathrm{A} \\
\mathrm{B} \\
\mathrm{C}\end{array}$ & $\begin{array}{l}\text { Buisson 1994. - D'ERrico et } \\
\text { al. } 2003 .\end{array}$ \\
\hline $\begin{array}{l}\text { Peyrat } \\
\text { (Frankreich) } \\
\text { (Abb. 4/9) }\end{array}$ & Magdalénien & 6 & $1,1-1,2$ & $\begin{array}{l}\text { Säugetierknochen mit } \\
4 \text { Löchern }\end{array}$ & $C$ ? & $\begin{array}{l}\text { Fages, Mourer-Chauviré } \\
1983 .\end{array}$ \\
\hline $\begin{array}{l}\text { Kammern- } \\
\text { Grubgraben } \\
\text { (Österreich) } \\
\text { (Abb. 4/10) }\end{array}$ & Magdalénien & 15,6 & $1,7-2,6$ & $\begin{array}{l}\text { Schienbein eines mittelgroßen } \\
\text { Huftieres mit } 3 \text { Löchern }\end{array}$ & - & $\begin{array}{l}\text { KäFER 1998. - EINWÖGERER, } \\
\text { KäFER, FLADERER } 1998 .\end{array}$ \\
\hline $\begin{array}{l}\text { Les Roches } \\
\text { bei Sergeac } \\
\text { (Frankreich) } \\
\text { (Abb. 4/11) }\end{array}$ & Périgordien (?) & 12,3 & $\begin{array}{c}\text { ca. } \\
1,8-2,9\end{array}$ & $\begin{array}{l}\text { Säugetierknochen mit } \\
2 \text { Löchern }\end{array}$ & - & Neal 2013. - Atema 2014. \\
\hline $\begin{array}{l}\text { Pas du Miroir } \\
\text { (Frankreich) } \\
\text { (Abb. 4/12) }\end{array}$ & Magdalénien & 16,6 & $1,8-2,9$ & $\begin{array}{l}\text { Limbus, } 4 \text { Löcher vorderseitig und } \\
2 \text { rückseitig }\end{array}$ & - & $\begin{array}{l}\text { Fages, Mourer-Chauviré } \\
\text { 1983. - Turk, Kavur } 1997 .\end{array}$ \\
\hline $\begin{array}{l}\text { Moldova V } \\
\text { (Ukraine) } \\
\text { (Abb. 4/13) }\end{array}$ & Magdalénien & $\begin{array}{l}19,6 \\
\text { oder } \\
21,0\end{array}$ & $\begin{array}{c}0,9-1,45 \\
\text { oder } \\
1,2-1,3\end{array}$ & $\begin{array}{l}\text { der Länge nach durchbohrtes } \\
\text { Rentiergeweih (innen 5-1 mm am } \\
\text { schmalen Ende); } 4 \text { Öffnungen in } \\
\text { einer Linie, am anderen Ende auf } \\
\text { der gegenüberliegenden Seite } 2 \\
\text { Öffnungen }\end{array}$ & - & $\begin{array}{l}\text { HäUSLER 1960. - Lucius } \\
\text { 1969-1970. - Fages, } \\
\text { Mourer-ChauvirÉ 1983. - } \\
\text { Hahn, MüNZEL } 1995 .\end{array}$ \\
\hline $\begin{array}{l}\text { Moldova V } \\
\text { (Ukraine) } \\
\text { (Abb. 4/14) }\end{array}$ & Ende der Altsteinzeit & $?$ & $?$ & $\begin{array}{l}\text { Hohles Hirschgeweih mit } 4 \text { und } 2 \\
\text { Löchern }\end{array}$ & - & $\begin{array}{l}\text { Fages, Mourer-Chauviré } \\
\text { 1983. - Turk, Kavur } 1997 .\end{array}$ \\
\hline $\begin{array}{l}\text { Moldova V } \\
\text { (Ukraine) } \\
\text { (Abb. 4/15) }\end{array}$ & Magdalénien & 19,5 & 1,4 & $\begin{array}{l}\text { Rengeweihstange (Halbfabrikat), } \\
\text { Längsaushöhlung 1-2 mm Dm; im } \\
\text { oberen Teil } 3 \text { vertikale Öffnungen } \\
\text { und Spuren von weiteren } 4 \text { in einer } \\
\text { Reihe; auf der gegenüberliegenden } \\
\text { Seite } 2 \text { Öffnungen; } 2 \text { Öffnungen } \\
\text { im unteren Teil, die erste bei der } \\
\text { Gabelung, die zweite an der Seite } \\
\text { (Luftauslassöffnung) }\end{array}$ & - & Lucius 1969-1970. \\
\hline
\end{tabular}


Tab. 3. Liste der vermeintlichen Aerophone (bzw. perforierten Knochen) des europäischen Jungpaläolithikums.

\begin{tabular}{|c|c|c|c|}
\hline Fundort & Datierung & Anmerkungen & Literatur \\
\hline $\begin{array}{l}\text { Bukovácer Höhle, auch } \\
\text { unter Fundort Lovke } \\
\text { (Kroatien) }\end{array}$ & $\begin{array}{l}\text { Frühes Jungpaläolithikum, } \\
\text { Olschewien (Aurignacien } \\
\text { nach FAGES, Mourer- } \\
\text { CHAUviRÉ 1983) }\end{array}$ & $\begin{array}{l}2 \text { Höhlenbärknochen mit } \\
1 \text { bzw. } 3 \text { Löchern }\end{array}$ & $\begin{array}{l}\text { FAges, Mourer-Chauviré 1983. - } \\
\text { Albrecht et al. 1998. - Holdermann, } \\
\text { Serangeli } 1998 .\end{array}$ \\
\hline $\begin{array}{l}\text { Drachenhöhle bei } \\
\text { Mixnitz (Österreich) }\end{array}$ & $\begin{array}{l}\text { Frühes Jungpaläolithikum, } \\
\text { Aurignacien }\end{array}$ & Bärenknochen mit 3 Löchern & MEGAW 1968. \\
\hline $\begin{array}{l}\text { Lieglloch, auch Liglloch } \\
\text { oder Liege Höhle } \\
\text { (Österreich) }\end{array}$ & $\begin{array}{l}\text { Frühes Jungpaläolithikum, } \\
\text { Aurignacien }\end{array}$ & $\begin{array}{l}2 \text { Höhlenbärknochen mit } \\
1 \text { bzw. } 4 \text { Löchern }\end{array}$ & $\begin{array}{l}\text { HoRUSitzKy 1954. - SCOTHERN 1992. - } \\
\text { Albrecht et al. 1998. - HoldermanN, } \\
\text { SERANGELI 1998. - Morley } 2013 .\end{array}$ \\
\hline $\begin{array}{l}\text { Große Badlhöhle } \\
\text { (Österreich) }\end{array}$ & Frühes Jungpaläolithikum & Höhlenbärknochen mit 1 Loch & $\begin{array}{l}\text { Albrecht et al. 1998. - Holdermann, } \\
\text { Serangeli } 1998 .\end{array}$ \\
\hline $\begin{array}{l}\text { Ramesch-Knochenhöhle } \\
\text { (Österreich) }\end{array}$ & ? (Oberflächenfund) & Bärenrippe mit 3 Löchern & $\begin{array}{l}\text { Albrecht et al. 1998. - Holdermann, } \\
\text { Serangeli } 1998 .\end{array}$ \\
\hline $\begin{array}{l}\text { Istállóskő-Höhle } \\
\text { (Ungarn) }\end{array}$ & $\begin{array}{l}\text { Frühes Jungpaläolithikum, } \\
\text { Aurignacien }\end{array}$ & $\begin{array}{l}\text { Femur eines Höhlenbären mit } 3 \\
\text { Löchern }\end{array}$ & $\begin{array}{l}\text { Fages, Mourer-Chauviré 1983. - } \\
\text { Albrecht et al. 1998. - Holdermann, } \\
\text { Serangeli } 1998 .\end{array}$ \\
\hline $\begin{array}{l}\text { Salzofenhöhle } \\
\text { (Österreich) }\end{array}$ & $\begin{array}{l}\text { Mittelpaläolithikum } \\
\text { (Aurignacien nach FAGES, } \\
\text { MourER-CHAUvirÉ 1983) }\end{array}$ & $\begin{array}{l}\text { Höhlenbärulna (Femur) mit } \\
1 \text { Loch ( } 2 \text { Löcher nach FAGEs, } \\
\text { Mourer-CHAuviré 1983) }\end{array}$ & $\begin{array}{l}\text { FAges, Mourer-Chauviré 1983. - } \\
\text { Albrecht et al. 1998. - Holdermann, } \\
\text { SERANGeli } 1998 .\end{array}$ \\
\hline $\begin{array}{l}\text { Potočka zijalka-Höhle } \\
\text { (Slowenien) }\end{array}$ & $\begin{array}{l}\text { Frühes Jungpaläolithikum, } \\
\text { Olschewien (Aurignacien } \\
\text { nach FAGES, Mourer- } \\
\text { CHAUviré 1983) }\end{array}$ & $\begin{array}{l}\text { Höhlenbärmandibula mit } \\
3 \text { Löchern (und großem } \\
\text { ausgebrochenen Loch) }\end{array}$ & $\begin{array}{l}\text { Seewald 1934. - Fages, Mourer- } \\
\text { Chauviré 1983. - Albrecht et al. 1998. - } \\
\text { Holdermann, Serangeli } 1998 .\end{array}$ \\
\hline $\begin{array}{l}\text { Ilsenhöhle bei Ranis } \\
\text { (Deutschland) }\end{array}$ & $\begin{array}{l}\text { Übergang zum } \\
\text { Jungpaläolithikum }\end{array}$ & $\begin{array}{l}\text { Ulna vom Schwein mit } \\
2 \text { Löchern (5 Löcher nach TURK, } \\
\text { KAvUR 1997) }\end{array}$ & Turk, Kavur 1997. - Albrechit et al. 1998. \\
\hline $\begin{array}{l}\text { Kents Cave / Cavern } \\
\text { (England) }\end{array}$ & Magdalénien & Hasenfemur mit 6 Löchern & $\begin{array}{l}\text { Seewald 1934. - Fages, Mourer- } \\
\text { ChauvirÉ } 1983 .\end{array}$ \\
\hline Divje babe I (Slowenien) & Mittelpaläolithikum & $\begin{array}{l}\text { Femur eines Höhlenbären mit } \\
2 \text { vollständigen Löchern (und } \\
\text { Anblaskerbe?) }\end{array}$ & $\begin{array}{l}\text { Turk 1997b. - Turk 1997c. - Albrecht et } \\
\text { al. 1998. - Holdermann, Serangeli } 1998 . \\
\text { - Turk et al. } 2018 .\end{array}$ \\
\hline
\end{tabular}




\section{Danksagung}

Ich bedanke mich vielmals bei den Teilnehmern des Ensembles SteinzeitSession (www.steinzeitmusik.com). Vielen Dank an Prof. Dr. Walter Leitner, Mag. Michael Schick und Dr. Elias Flatscher vom Institut für Archäologien sowie insbesondere Prof. Dr. Raymond Ammann vom Institut für Musikwissenschaft der Leopold-Franzens-Universität Innsbruck. Dieser Artikel profitierte von zahlreichen neuen Denkanstößen und Anregungen, die der Verfasser bei zwei Symposien mit der International Council for Traditional Music (ICTM) Study Group in Slowenien (2017) und Brandenburg (2018) sammeln konnte. Ich danke an dieser Stelle allen Beteiligten. Besten Dank auch an die anonymen GutachterInnen, Redaktion und Grafikabteilung der „Archaeologia Austriaca“.

\section{Literatur}

Albrecht, Holdermann, Serangeli 2001

G. Albrecht, C.-S. Holdermann, J. Serangeli, Towards an archaeological appraisal of specimen $\mathrm{n}^{\circ} 652$ from Middle Palaeolithic level D / (layer 8) of the Divje babe I, Arheološki vestnik $52,2001,11-15$.

Albrecht et al. 1998

G. Albrecht, C.-S. Holdermann, T. Kerig, J. Leuchterbeck, J. Serangeli, „Flöten“ aus Bärenknochen - die frühesten Musikinstrumente? Archäologisches Korrespondenzblatt 28, 1998, 1-19.

Allain 1950

J. Allain, Un appeau Magdalénien, Bulletin de la Société Préhistorique Française 47/3-4, 1950, 181-192.

Ammann 2012

R. Ammann, Sounds of Secrets: Field Notes on Ritual Music and Musical Instruments on the Islands of Vanuatu. KlangKulturStudien 7, Zürich - Berlin 2012.

Ammann, Praxmarer im Druck

R. Ammann, M. Praxmarer, Cognitive music archaeology, a new trend in ethnomusicology: interdisciplinary research on Paleolithic musical instruments, Stone Age flutes from the 3D printer. In: G. Grupe (Hrsg.), Recent Trends and New Directions in Ethnomusicology: A European Perspective on Ethnomusicology in the $21^{\text {st }}$ Century. Grazer Beiträge zur Ethnomusikologie / Graz Studies in Ethnomusicology 26, im Druck.

Atema 2004

J. Atema, Old bone flutes, Pan - Journal of the British Flute Society $23,2004,18-23$.

Atema 2014

J. Atema, Musical origins and the Stone Age evolution of flutes, Acoustics Today 14/2, 2014, 26-34.

Auhagen 1994

W. Auhagen, Instrumentenakustik: Blasinstrumente. In: L. FinSCHER (Hrsg.), Die Musik in Geschichte und Gegenwart, Sachteil 1. Stuttgart - Kassel 1994, 385-394.

BALFOUR, BLACKWOOD 1948

H. Balfour, B. M. Blackwood, Ritual and secular uses of vibrating membranes as voice disguisers, The Journal of the Royal Anthropological Institute of Great Britain and Ireland 78/1-2, 1948, 45-69.

BATLUND 1994

B. BATLUND, A survey of the subsistence and settlement pattern of the Hamburgian culture in Schleswig-Holstein, Jahrbuch des Römisch-Germanischen Zentralmuseums Mainz 41, 1994, 59-93.
Benade 1988

A. H. Benade, Holzblasinstrumente. In: K. Winkler (Hrsg.), Die Physik der Musikinstrumente. Spektrum der Wissenschaft, Heidelberg 1988, 22-32.

Berghaus 2004

G. Berghaus, The discovery and study of prehistoric art. In: G. Berghaus (Hrsg.), New Perspectives on Prehistory of Art. Westport, Conn. 2004.

BOSINSKI, FisCHER 1974

G. Bosinski, G. Fischer, Die Menschendarstellungen von Gönnersdorf der Ausgrabung von 1968. Der Magdalénien-Fundplatz Gönnersdorf 1, Wiesbaden 1974.

BROWN 2000

S. BRown, The 'musilanguage' model of music evolution. In: N. L. Wallin, B. Merker, S. Brown (Hrsg.), The Origins of Music. Cambridge, Mass. 2000, 27-29.

Buisson 1990

D. Buisson, Les flûtes paléolithiques d'Isturitz (Pyrénées-Atlantiques), Bulletin de la Société Préhistorique Française 87/10-12, 1990, 420-433.

Buisson 1994

D. Buisson, Les flûtes paléolithiques d'Isturitz. In: C. Номо-LeCHNER, A. BÉLIs (Hrsg.), La pluridisciplinarité en archéologie musicale I. IVe Rencontres internationales d'archéologie musicale de l'ICTM, Saint-Germain-en-Laye, 8-12 octobre 1990. Paris 1994, 259-275.

Caldwell 2009

D. Caldwelle, Palaeolithic whistles or figurines? A preliminary survey of prehistoric phalangeal figurines, Rock Art Research 26/1, 2009, 65-82.

Clottes, Lewis-Williams 1997

J. Clottes, D. Lewis-Williams, Schamanen: Trance und Magie in der Höhlenkunst der Steinzeit. Stuttgart 1997.

Conard, Malina, Münzel 2009

N. J. Conard, M. Malina, S. C. Münzel, New flutes document the earliest musical tradition in southwestern Germany, Nature 460/6, 2009, 737-740.

CONARD et al. 2004

N. J. Conard, M. Malina, S. C. Münzel, F. Seeberger, Eine Mammutelfenbeinflöte aus dem Aurignacien des Geißenklösterle: Neue Belege für eine musikalische Tradition im frühen Jungpaläolithikum auf der Schwäbischen Alb, Archäologisches Korrespondenzblatt 34/4, 2004, 447-462.

DAms 1985

L. DAms, Palaeolithic lithophones: descriptions and comparisons, Oxford Journal of Archaeology 4, 1985, 31-46.

Dauvois 1989

M. Dauvois, Son et musique paléolithiques, Les Dossiers d'Archéologie 142, 1989, 2-11.

Dauvois 1994

M. DAuvois, Les témoins sonores paléolithiques, extérieur et souterrain. In: M. Отте (Hrsg.), Sons originels: Préhistorie de la musique. Études et Recherches Archéologiques de l’Université de Liège 61, Lüttich 1994, 11-31.

Dauvois 2005

M. DAuvors, Homo musicus palaeolithicus et palaeoacustica, Munibe Antropologia-Arkeologia 57, 2005, 225-241. 
D’ERrico 2002

F. D'Errico, Just a bone or a flute? The contribution of taphonomy and microscopy to the identification of prehistoric pseudo-musical instruments. In: E. Hickmann, A. D. Kilmer, R. Eichmann (Hrsg.), Studien zur Musikarchäologie III. Orient-Archäologie 10, Rahden/Westf. 2002, 89-91.

D’Errico, Villa 1997

F. D'Errico, P. Villa, Holes and grooves: the contribution of microscopy and taphonomy to the problem of art origins, Journal of Human Evolution 33, 1997, 1-31.

D’Errico et al. 1998

F. D’Errico, J. Zilhão, M. Julien, D. Baffier, J. Pelegrin, Neanderthal acculturation in western Europe? A critical review of the evidence and its interpretation, Current Anthropology 39, 1998, 1-44.

D’Errico et al. 2003

F. D’Errico, C. Henshilwood, G. Lawson, M. Vanhaeren, A.-M. Tillier, M. Soressi, F. Bresson, B. Maureille, A. Nowell, J. Lakarra, L. Backwell, M. Julien, Archaeological evidence for the emergence of language, symbolism and music: an alternative multidisciplinary perspective, Journal of World Prehistory 17/1, 2003, 1-70.

EINWÖGERER, KäFER, FLADERER 1998

T. EinwÖgerer, B. KäFer, F. A. Fladerer, Eine jungpaläolithische Knochenflöte aus der Station Grubgraben bei Kammern, Niederösterreich, Archäologisches Korrespondenzblatt 28, 1998, 21-30.

EMSHEIMER 1947

E. Emsheimer, A Lapp musical instrument, Ethnos 12/1-2, 1947, $86-92$.

Fages, Mourer-Chauviré 1983

G. Fages, C. Mourer-Chauviré, La flûte en os d'oiseau de la grotte sépulcrale de Veyreau (Aveyron) et inventaire des flûtes préhistoriques d'Europe. In: F. Poplin (Hrsg.), La faune et l'homme préhistorique. Dix études en hommage à Jean Bouchud. Mémoires de la Société Préhistorique Française 16, Paris 1983, 95-103.

FeLiks 2011

J. Feliks, The golden flute of Geissenklösterle: mathematical evidence for a continuity of human intelligence as opposed to evolutionary change through time, Journal of Applied Mathematics 4/4, 2011,157-162.

FRANZ 1969

L. Franz, Die Kultur der Urzeit Europas. Handbuch der Kulturgeschichte, 2. Abteilung: Kulturen der Völker, Frankfurt 1969.

Grauer 2006

V. A. Grauer, Echoes of our forgotten ancestors, The World of Music 48/2, 2006, 5-59.

GraUer 2011

V. A. Grauer, Sounding the Depths: Tradition and the Voices of History. Ohne Ort 2011

Hahn, MünZEL 1995

J. Hahn, S. Münzel, Knochenflöten aus dem Aurignacien des Geißenklösterle bei Blaubeuren, Alb-Donau-Kreis, Fundberichte aus Baden-Württemberg 20, 1995, 1-12.

Hall 1997

D. E. Hall, Musikalische Akustik: Ein Handbuch. Mainz 1997.

HÄUSLER 1960

A. HäUSLER, Neue Funde steinzeitlicher Musikinstrumente in Osteuropa, Acta Musicologica 32/2-3, 1960, 151-155.
HeIn 1998

W. HeIn, Zur Rekonstruktion und Funktion jungpaläolithischer Knochenflöten, Musica Instrumentalis 1, 1998, 120-128.

Henshilwood, D'Errico 2011

C. S. Henshilwood, F. D’Errico (Hrsg.), Homo Symbolicus: The Dawn of Language, Imagination and Spirituality. Amsterdam Philadelphia 2011.

Higham et al. 2012

T. Higham, L. Basell, R. Jacobi, R. Wood, C. Bronk-Ramsey, N. J. Conard, Testing models for the beginnings of the Aurignacien and the advent of figurative art and music: the radiocarbon chronology of Geißenklösterle, Journal of Human Evolution 62/6, 2012, 664-676.

Нітснсоск 2019

D. Нітснсоск, The Kostenki-Borshevo, Костенки-Борщево region on the Don River, https://donsmaps.com/lioncamp.html (letzter Zugriff 21.8.2019).

HOLDERMANN 2001

C.-S. Holdermann, Musik und Tanz. In: H. Müller-Beck, N. J. Conard, W. Schürle (Hrsg.), Eiszeitkunst im Süddeutsch-Schweizerischen Jura: Anfänge der Kunst. Stuttgart 2001, 88-94.

Holdermann, Serangeli 1998

C.-S. Holdermann, J. Serangeli, Einige Bemerkungen zur „Flöte“ von Divje babe I (Slowenien) und deren Vergleichsfunde aus dem österreichischen Raum und angrenzenden Gebieten, Archäologie Österreichs 9/2, 1998, 31-38.

Hornbostel, Sachs 1914

E. M. Hornbostel, C. Sachs, Systematik der Musikinstrumente: Ein Versuch, Zeitschrift für Ethnologie 46, 1914, 553-590.

HORUSITZKY 1954

Z. Horusitzky, Eine Knochenflöte aus der Höhle von Istállóskő, Acta Archaeologica Academiae Scientarum Hungaricae 5, 1954, 133-145.

IBÁÑ̃Z et al. 2015

J. J. Ibáñez, J. Salius, I. Clemente-Conte, N. Soler, Use and sonority of a 23,000-year-old bone aerophone from Davant Pau Cave (NE of the Iberian Peninsula), Current Anthropology 56/2, 2015, 282-289.

JUNKMANNS 2013

J. Junkmanns, Pfeil und Bogen: Von der Altsteinzeit bis zum Mittelalter. Ludwigshafen 2013.

KÄFER 1998

B. KäFER, Paläolithische Knochenflöten im Ostalpenraum und dem nordöstlich vorgelagerten Lößgebiet. Diplomarbeit, Hochschule für Musik und darstellende Kunst Wien 1998.

KERIG 2009

T. Kerig, Steinzeitliche Nachklänge? Eine Ethnoarchäologie der Musik. In: Eiszeit: Kunst und Kultur (Begleitband zur Großen Landesausstellung Baden-Württemberg, Stuttgart, 18.9.200910.1.2010). Ostfildern 2009, 327-331.

KiLLin 2018

A. KILLIN, The origins of music: evidence, theory and prospects, $\mathrm{Mu}-$ sic \& Science 1, 2018, 1-23.

KNOCHENKLANG 2000

Ensemble Knochenklang, Knochenklang: Klänge aus der Steinzeit. Audio CD und Booklet. Mitteilungen der Prähistorischen Kommission 36, Wien 2000. 


\section{KuneJ 1997}

D. KunEJ, Akustične ugotovitve na podlagi rekonstrukcije domnevne koščene piščali / Acoustic results on the basis of the reconstruction of a presumed bone flute. In: I. TuRk (Hrsg.), Mousteriénska „koščena piščal“ in druge najdbe iz Divjih bab I v Sloveniji / Mousterian "Bone Flute" and other Finds from Divje Babe I Cave Site in Slovenia. Opera Instituti Archaeologici Sloveniae 2, Ljubljana 1997, 185-198.

KuneJ, Turk 2000

D. Kunej, I. Turk, New perspectives on the beginnings of music: archaeological and musicological analysis of a Middle Paleolithic bone „flute”. In: N. L. Wallin, B. Merker, S. Brown (Hrsg.), The Origins of Music. Cambridge, Mass. 2000, 235-268.

Lawson, D'ERrico 2002

G. Lawson, F. D'Errico, Microscopic, experimental and theroretical re-assessment of Upper Palaeolithic bird-bone pipes from Isturitz, France. Ergonomics of design, systems of notation and the origins of musical traditions. In: E. Hickmann, A. D. Kilmer, R. Eichmann (Hrsg.), Studien zur Musikarchäologie III. Orient-Archäologie 10, Rahden/Westf. 2002, 119-142.

LORBLANCHET 1997

M. Lorblanchet, Höhlenmalerei: Ein Handbuch. Sigmaringen 1997.

LOTTERMOSER 1983

W. Lottermoser, Orgeln, Kirchen und Akustik. Frankfurt/Main 1983.

Lucius 1969-1970

E. Lucius, Das Problem der Chronologie jungpaläolithischer Stationen im Bereiche der europäischen UdSSR. Mitteilungen der Prähistorischen Kommission 13-14, Wien 1969-1970.

Mauser 1970

P. F. Mauser, Die jungpaläolithische Station Petersfels im Hegau. Badische Fundberichte Sonderheft 13, Freiburg 1970.

Megaw 1960

J. V. S. Megaw, Penny whistles and prehistory, Antiquity 34/133, 1960, 3-13.

Megaw 1968

J. V. S. Megaw, Problems and non-problems in palaeo-organology: a musical miscellany. In: J. M. Coles, D. D. A. Simpson (Hrsg.), Studies in Ancient Europe. Essays Presented to Stuart Piggott. Leicester 1968, 333-358.

Mellars 2010

P. Mellars, Neanderthal symbolism and ornament manufacture: the bursting of a bubble? Proceedings of the National Academy of Sciences of the United States of America 107/47, 2010, 20147-20148.

MeYer 1977

E. H. Meyer (Hrsg.), Geschichte der Musik: 1. Musik der Urgesellschaft und der frühen Klassengesellschaften. Leipzig 1977.

Meyer, Meyer, Betz 1995

J. Meyer, A. Meyer, M. Betz, Flöten. In: L. Finscher (Hrsg.), Die Musik in Geschichte und Gegenwart, Sachteil 3. Stuttgart 1995, 559-563.

Мıмо 2011

Revision of the Hornbostel-Sachs Classification of Musical Instruments by the MIMO Consortium. http://network.icom. museum/fileadmin/user_upload/minisites/cimcim/documents/ H-S_20classification_20final_20version_20_282013_29_20wit hout_20editorial_20markings-2.pdf (letzter Zugriff 21.8.2019).
Mithen 1996

S. Mithen, The Prehistory of Mind: A Search for the Origin of Art, Science and Religion. London 1996.

Mithen 2005

S. Mithen, The Singing Neanderthals: The Origins of Music, Language, Mind and Body. London 2005.

Modl, Pacher 2014

D. Modr, M. Pacher, Die Pseudoartefakte und der Wolfszahnanhänger aus der Repolusthöhle (Steiermark, Österreich): Mit einem Diskussionsbeitrag zum Neandertaler und dem Mittelpaläolithikum im Südostalpenraum, Schild von Steier 26/20132014, 2014, 175-211.

MORLEY 2003

I. Morley, The Evolutionary Origins and Archaeology of Music: An Investigation into the Prehistory of Human Musical Capacities and Behaviours, Using Archaeological, Anthropological, Cognitive and Behavioural Evidence. Dissertation, University of Cambridge 2003

MORLEY 2013

I. Morley, The Prehistory of Music: Human Evolution, Archaeology and the Origins of Musicality. Oxford 2013.

MüLleR-Beck 2001a

H. Müller-Beck, Plastiken: Aurignacien. In: H. Müller-Beck, N. J. ConARD, W. SchürLE (Hrsg.), Eiszeitkunst im SüddeutschSchweizerischen Jura: Anfänge der Kunst. Stuttgart 2001, 48-51.

MüLleR-Beck 2001b

H. MÜLLER-BECK, Gravierungen und gravierte Marken: Aurignacien. In: H. Müller-Beck, N. J. Conard, W. Schürle (Hrsg.), Eiszeitkunst im Süddeutsch-Schweizerischen Jura: Anfänge der Kunst. Stuttgart 2001, 59-68.

MÜnzel, CONARD 2009

S. C. Münzel, N. J. Conard, Flötenklang aus fernen Zeiten: Die frühesten Musikinstrumente. In: Eiszeit: Kunst und Kultur (Begleitband zur Großen Landesausstellung Baden-Württemberg, Stuttgart, 18.9.2009-10.1.2010). Ostfildern 2009,317-321.

MüNZel et al. 2015

S. C. Münzel, W. Hein, F. Potengowski, N. J. Conard, Flötenklang aus fernen Zeiten: Die ältesten Blasinstrumente von der Schwäbischen Alb. In: R. Eichmann, L.-C. Koch (Hrsg.), Musikarchäologie: Klänge der Vergangenheit. Archäologie in Deutschland Sonderheft 7, Darmstadt 2015, 30-37.

MüNZel et al. 2016

S. C. Münzel, N. J. Conard, W. Hein, F. Gill, A. F. Potengowski, Interpreting three Upper Palaeolithic wind instruments from Germany and one from France as flutes: (re)construction, playing techniques and sonic results. In: R. Eichmann, L.-C. KocH, F. Jianjun (Hrsg.), Studien zur Musikarchäologie X: Klang Objekt - Kultur - Geschichte. Vorträge des 9. Symposiums der Internationalen Studiengruppe Musikarchäologie im Ethnologischen Museum der Staatlichen Museen zu Berlin, 9.-12. September 2014. Orient-Archäologie 37, Rahden/Westf. 2016, 225-243.

Napierala, Uerpmann 2009

H. Napierala, H.-P. Uerpmann, Jäger und Gejagte: Eiszeitliche Großwildjagd in der Mammutsteppe. In: Eiszeit: Kunst und Kultur (Begleitband zur Großen Landesausstellung BadenWürttemberg, Stuttgart, 18.9.2009-10.1.2010). Ostfildern 2009, 186-190. 
NeAL 2013

L. C. Neal, The Earliest Instrument: Ritual Power and Fertility Magic of the Flute in Upper Paleolithic Culture. Dissertation, University of Texas at Austin 2013, http://repositories.lib. utexas.edu/handle/2152/28717 (letzter Zugriff 21.8.2019).

Neugebauer-Maresch 1989

C. Neugebauer-Maresch, Zum Neufund einer weiblichen Statuette bei den Rettungsgrabungen an der Aurignacien-Station Stratzing/Krems-Rehberg, Niederösterreich, Germania 67/2, 1989, 551-559.

Neugebauer-Maresch 1990

C. Neugebauer-Maresch, Zum Neufund einer 30000 Jahre alten weiblichen Statuette bei Krems, Antike Welt 21/1, 1990, 3-13.

Nowell, D’Errico 2007

A. Nowell, F. D'Errico, The art of taphonomy and the taphonomy of art: Layer IV, Molodova I, Ukraine, Journal of Archaeological Method and Theory 14/1, 2007, 1-26.

OMERZEL-TERLEP 1997

M. Omerzel-Terlep, Tipologija koščenih žvižgavk, piščali in flavt ter domnevna paleolitska phala Slovenije / A typology of bone whistles, pipes and flutes and presumed palaeolithic wind instruments in Slovenia. In: I. Turk (Hrsg.), Mousteriénska „koščena piščal" in druge najdbe iz Divjih bab I v Sloveniji / Mousterian "Bone Flute" and other Finds from Divje Babe I Cave Site in Slovenia. Opera Instituti Archaeologici Sloveniae 2, Ljubljana 1997, 199-212.

POMBERgER 2016

B. M. Pomberger, Wiederentdeckte Klänge: Musikinstrumente und Klangobjekte vom Neolithikum bis zur römischen Kaiserzeit im mittleren Donauraum. Universitätsforschungen zur prähistorischen Archäologie 280, Bonn 2016.

RiNGOT 2011

J.-L. Ringot, Die steinzeitlichen Aerophone: Flöten oder Schalmeien? Experimentelle Archäologie in Europa 10, 2011, 188-198.

RINGOT 2012

J.-L. Ringot, Upper Paleolithic aerophones - flute or pipe? An experimental approach: summary report. In: R. Eichmann, F. Jianjun, L.-C. Косн (Hrsg.), Studien zur Musikarchäologie VIII. Orient-Archäologie 27, Rahden/Westf. 2012, 389-391.

ROTTLÄNDER 1996

R. C. A. Rottränder, Frühe Flöten und die Ausbildung der musikalischen Hörgewohnheiten des paläolithischen Menschen. In: I. Campen, J. Hahn, M. Uerpmann (Hrsg.), Spuren der Jagd - Jagd nach Spuren. Festschrift für Hansjürgen Müller-Beck. Tübinger Monographien zur Urgeschichte 11, Tübingen 1996, $35-40$.

SACHS 1940

C. SACHS, The History of Musical Instruments. New York 1940.

SAINZ 1989

C. G. SAInZ, El Magdaleniese Superior: Final de la región cantábrica. Santander 1989.

SCHULER 1994

A. Schuler, Die Schussenquelle: Eine Freilandstation des Magdalénien in Oberschwaben. Materialhefte zur Archäologie in BadenWürttemberg 27, Stuttgart 1994.

SCOTHERN 1992

P. M. T. Scothern, The Music-archaeology of the Palaeolithic within its Cultural Setting. Dissertation, University of Cambridge 1992.
SeEberger 2002

F. SeEberger, Steinzeit selbst erleben! Waffen, Schmuck und Instrumente - nachgebaut und ausprobiert. Stuttgart 2002.

SeEberger 1998

F. Seeberger, Zur Spielweise paläolithischer Knochenflöten, Archäologisches Korrespondenzblatt 28, 1998, 31-33.

SEewald 1934

O. SeEwald, Beiträge zur Kenntnis der steinzeitlichen Musikinstrumente Europas. Wien 1934.

Stumpf 1911

C. Stumpf, Die Anfänge der Musik. Leipzig 1911.

TAMboer 1999

A. Тамвоer, Ausgegrabene Klänge: Archäologische Musikinstrumente aus allen Epochen. Archäologische Mitteilungen aus Nordwestdeutschland, Beiheft 25, Oldenburg 1999.

Tomedi 2001

G. Tomedi, Zur vorgeschichtlichen Musik im Raum Alttirol und im Südalpenraum. In: K. DreXeL, M. Fink (Hrsg.), Musikgeschichte Tirols 1: Von den Anfängen bis zur frühen Neuzeit. SchlernSchriften 315, Innsbruck 2001, 11-35.

ToMLinson 2015

G. Tomlinson, A Million Years of Music: The Emergence of Human Modernity. New York 2015.

TURK 1997a

I. TuRK (Hrsg.), Mousteriénska „koščena piščal“ in druge najdbe iz Divjih bab I v Sloveniji / Mousterian "Bone Flute" and other Finds from Divje Babe I Cave Site in Slovenia. Opera Instituti Archaeologici Sloveniae 2, Ljubljana 1997.

TuRK $1997 \mathrm{~b}$

I. TuRK, Uvod / Introduction. In: I. TuRK (Hrsg.), Mousteriénska „koščena piščal“ in druge najdbe iz Divjih bab I v Sloveniji / Mousterian "Bone Flute" and other Finds from Divje Babe I Cave Site in Slovenia. Opera Instituti Archaeologici Sloveniae 2, Ljubljana 1997, 19-24.

TuRK 1997c

I. TURK, Stratgrafija in diageneza usedlin / Stratigraphy and diagenesis of sediments. In: I. TuRk (Hrsg.), Mousteriénska „koščena piščal" in druge najdbe iz Divjih bab I v Sloveniji / Mousterian "Bone Flute" and other Finds from Divje Babe I Cave Site in Slovenia. Opera Instituti Archaeologici Sloveniae 2, Ljubljana 1997, 25-40.

Turk, Kavur 1997

I. Turk, B. Kavur, Paleolitske koščene piščali: primerjalno gradivo / Palaeolithic bone flutes: comparable material. In: I. TuRk (Hrsg.), Mousteriénska „koščena piščal“ in druge najdbe iz Divjih bab I v Sloveniji / Mousterian "Bone Flute" and other Finds from Divje Babe I Cave Site in Slovenia. Opera Instituti Archaeologici Sloveniae 2, Ljubljana 1997, 179-184.

Turk, Dirjec, Kavur 1995

I. Turk, J. Dirjec, B. Kavur, Ali so Sloveniji nasli najstarejse glasbilo? / The oldest musical instrument in Europe discovered in Slovenia? Razprave IV, Razreda Slovenska Akademija Znanosti in Umetnosti 36, 1995, 287-293.

Turk et al. 2018

M. Turk, I. Turk, L. Dimkaroski, B. A. B. Blackwell, F. Z. Horusitzky, M. Otte, G. Bastiani, L. Korat, The Mousterian musical instrument from the Divje babe I cave (Slovenia): arguments on the material evidence for Neanderthal musical behaviour, L’Anthropologie 122/4, 2018, 679-706. 
VANHAEREN et al. 2006

M. Vanhaeren, F. D’Errico, C. Stringer, S. L. James, J. A. Todd, H. K. Mienis, Middle Paleolithic shell beads in Israel and Algeria, Science 312/5781, 2006, 1785-1788.

WINKLER 1988

K. Winkler (Hrsg.), Die Physik der Musikinstrumente. Spektrum der Wissenschaft, Heidelberg 1988.

WILSON 1896

T. Wilson, Prehistoric Art or the Origin of Art as Manifested in the Works of Prehistoric Man, Smithsonian Institution Report of National Museum, 1896, 325-664.

WYATT 2012

S. WYATT, Sound production in early aerophones: short report on a work in progress. In: R. Eichmann, F. Jianjun, L.-C. Koch (Hrsg.), Studien zur Musikarchäologie VIII. Orient-Archäologie 27, Rahden/Westf. 2012, 393-398.

WYATT 2016

S. WYATT, Whistle up a storm: a further report on sound production in early aerophones. In: R. Eichmann, L.-C. Koch, F. Jianjun (Hrsg.), Studien zur Musikarchäologie X: Klang - Objekt - Kultur - Geschichte. Vorträge des 9. Symposiums der Internationalen Studiengruppe Musikarchäologie im Ethnologischen Museum der Staatlichen Museen zu Berlin, 9.-12. September 2014. Orient-Archäologie 37, Rahden/Westf. 2016, 201-212.

ZaGIBA 1976

F. Zagiba, Musikgeschichte Mitteleuropas I: Erster Teil. In: F. ZaGiba (Hrsg.), Forschungen zur älteren Musikgeschichte. Veröffentlichungen des Musikwissenschaftlichen Institutes der Universität Wien, Wien 1976, 7-59.

Michael Praxmarer

Dorfplatz 5

6170 Zirl

Österreich

much.praxmarer@gmail.com

iD orcid.org/0000-0002-2054-8554 
